Research Library Issues

RLI 296

2018
/ ASSOCIATION

LIBRARIES 


\section{In This Issue}

Why Does Research Data Management Need Radical Collaboration?

Radical Collaboration and Research Data Management: An Introduction

Radical Collaboration: Framing the Concept

Using Working Definitions to Build Understanding

What Makes Collaboration Radical?

Coming Together

Sharing the Table

Emerging Distributed Digital Practice

Building (an Inclusive) Community

Some Guiding Principles for Radical Collaboration

The Radical Collaboration of RDA and What It Means for Developing Institutional Data

Management Services

The Evolution of Collaboration

Encouraging Radical Collaboration

Bringing Everyone to the Table

Archives and Data Management: The Purdue Story 33

Barriers to Collaboration: Lessons Learned from the Data Curation Network 37

What is Open Science, and How Can Radical Collaboration Facilitate It? 44

Example 1. Radical Collaboration in Support of Open Science: Software Citation

Example 2. Radical Collaboration to Preserve Informal Astronomical Communications

Seeking Sustainability and Inclusivity with Transparent Practices for RDM

Making Research Data Management a Social Activity

Radical Collaboration: An Archival View

Disambiguating Digital Archives and Digital Preservation

Digital Practice and Research Outcomes

Considerations for Radical Collaboration That Engages Archives and Archivists

Forward Together

Navigating Our Shared Space(s)

What Could Radical Collaboration Look Like?

Example 1. Constructive Research Methodology Overview

Example 2. Storytelling as a Digital Preservation Strategy

How Can We Achieve Radical Collaboration? 


\section{Why Does Research Data Management Need Radical Collaboration?}

Judy Ruttenberg, Program Director for Strategic Initiatives, Association of Research Libraries

Elizabeth A. Waraksa, Program Director for Research and Strategic Initiatives, Association of Research Libraries

With this issue of Research Library Issues ( $R L I)$, the Association of Research Libraries (ARL) (re)turns its collective attention to research data management ( $\mathrm{RDM})$, a topic consistently identified as a top priority by ARL library directors, and a topic of several recent ARL publications-see for example SPEC Kit 334 on Research Data Management Services (2013) ${ }^{1}$ and SPEC Kit 354 on Data Curation (2017). ${ }^{2}$ Here, however, the focus is not so much the data itself as the human labor that goes into curating, preserving, and making data accessible and reusable-those fruitful collaborations across domains that allow "organizations and individuals...to identify and solve problems together, to achieve more together than we could separately," in the words of Nancy McGovern. ${ }^{3}$ The thesis offered here is that not only is RDM an ideal scenario for exploring radical collaboration, but that this kind of collaboration has already resulted in demonstrable success in the RDM arena and thus ought to be considered as a model for both nascent and future data management efforts.

Research data management is challenging, and many voices are needed to tackle this evolving effort-most crucially, the combined voices of archivists, librarians, and the data creators themselves. In opening this issue of $R L I$, Nancy McGovern offers definitions and guiding principles for bringing these diverse voices to the table and sustaining radical collaboration, while Amy Nurnberger, in a companion piece, describes this practice in action with the Research Data Alliance.

Research data management is a team effort by virtue of its nature; it has never been a solo or siloed endeavor. Purdue University, one of 
the pioneer institutions in this regard, recognized the importance of archival theory and practice to the emerging practice of RDM. Carly Dearborn, in her history of the Purdue University Research Repository (PURR) and Purdue's continuing efforts to engage archivists and data librarians in data management coursework, highlights many of the ways in which archival expertise can be leveraged in collaborative data management efforts. Lisa Johnston offers lessons learned from the early stages of the Data Curation Network, an initiative that brings together the perspectives of research data librarians, academic library administrators, and domain subject experts from academic libraries and ...not only is RDM an ideal scenario for exploring radical collaboration, but...this kind of collaboration has already resulted in demonstrable success.... general-purpose or disciplinary data repositories-the "human layer" in the technology stack, in Johnston's words-to share data curation expertise at the network level. Furthering the point about effective teaming is Megan Potterbusch, who offers two case studies of radical collaboration in support of open science: the development of Software Citation Principles, and the preservation of informal communication and gray literature in the astronomy community.

What therefore emerges in this issue, and within McGovern's frame of radical collaboration specifically, is a picture of the communities of practice that have developed in recent years to tackle so many of the thorny issues around RDM. In this vein, Heather Soyka shares her experience with DataONE as a means to consider the sustainability of these communities, above and beyond the sustainability of data itself. Additionally, Nancy McGovern offers inspiration for a new community of practice in archives, libraries, and team science utilizing the radical collaborative approach.

So why this issue, why now? This is a pivotal moment for the global research enterprise, in which researchers, institutions, and funders are 
wrestling with data management and curation in a variety of contexts. Libraries and archives will be vital partners within their institutions, and within the research enterprise, in implementing best practices for research data management by leveraging archival workflows for managing, curating, and preserving ever-evolving forms of content. This issue of $R L I$ is an important step in the process of building community across library and archival domains in support of this essential work.

\section{Endnotes}

1. David Fearon Jr., Betsy Gunia, Sherry Lake, Barbara E. Pralle, and Andrew L. Sallans, Research Data Management Services, SPEC Kit 334 (Washington, DC: Association of Research Libraries, July 2013), https://doi.org/10.29242/spec.334.

2. Cynthia Hudson-Vitale, Heidi Imker, Lisa R. Johnston, Jake Carlson, Wendy Kozlowski, Robert Olendorf, and Claire Stewart, Data Curation, SPEC Kit 354 (Washington, DC: Association of Research Libraries, May 2017) https://doi.org/10.29242/spec.354.

3. Nancy Y. McGovern, "Radical Collaboration and Research Data Management: An Introduction," Research Library Issues, no. 296 (2018): 6-22, https://doi.org/10.29242/rli.296.2.

(c) 2018 Judy Ruttenberg and Elizabeth A. Waraksa

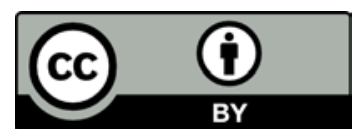

This article is licensed under a Creative Commons Attribution 4.0 International License. To view a copy of this license, visit https:// creativecommons.org/licenses/by/4.0/.

To cite this article: Judy Ruttenberg and Elizabeth A. Waraksa. "Why Does Research Data Management Need Radical Collaboration?" Research Library Issues, no. 296 (2018): 3-5. https://doi.org/10.29242/ rli.296.1. 


\section{Radical Collaboration and Research Data Management: An Introduction}

Nancy Y. McGovern, Director, Digital Preservation, MIT Libraries

\section{Radical Collaboration: Framing the Concept ${ }^{1}$}

Engaging in good practice for managing digital content and collections for the long-term increasingly brings domains together in new and/or unfamiliar ways. Addressing short- and long-term opportunities and challenges for research data management brings together diverse skills, experience, and perspectives of creators and curators across archives, libraries, museums and other academic organizations. As a scenario for exploring radical collaboration, research data management is ideal-a timely and high-profile community space that benefits from and increasingly requires working together to achieve common objectives.

The concept of radical collaboration means coming together across disparate, but engaged, domains in ways that are often unfamiliar or possibly uncomfortable to member organizations and individuals in order to identify and solve problems together, to achieve more together than we could separately. In this discussion, radical collaboration adapts the concept of radical candor to the desire and need to work together productively and collectively.

This introduction provides working definitions of key concepts and terms to make radical collaboration possible, explores some

...radical collaboration means coming together across disparate, but engaged, domains in ways that are often unfamiliar or possibly uncomfortable...to achieve more together than we could separately. possible approaches and opportunities, and suggests some considerations and implications for engaging in radical collaboration. In subsequent sections of this issue of $R L I$, contributing authors explore examples 
and aspects of collaboration leading to radical collaboration, and the concluding section suggests a path forward and some principles to guide that path towards radical collaboration.

\section{Using Working Definitions to Build Understanding}

Developing working definitions to build and ensure a shared understanding of core concepts is an effective tool for community building and for engaging in radical collaboration. The term "working definition" itself is a core concept for radical collaboration. When a new collaboration starts, members bring their individual and often idiosyncratic definitions with them, often unaware that others may understand these terms very differently. It is easy to avoid this frequent stumbling block to working together across domains-begin each new initiative with a review of terms and by filling in gaps in required terms, sharing them with new members as the group grows as part of an essential orientation process.

In practice, formal definitions, like those found in glossaries, emerge in a community once practice has been agreed upon and formalized and members have an increasingly mutual understanding of concepts and principles. At early stages of community development, before formal definitions emerge, it is common to find that the same terms mean different things in different domains and to members within the same domain. Using terms differently as domains come together to collaborate leads to ambiguity and confusion that presents a challenge for community building. Developing and sharing working definitions is a way to deepen and broaden understanding as we come together to work on shared objectives. We can extend and clarify working definitions as needed, so they provide a great tool for bringing different experiences and perspectives together, for forging a shared understanding.

This section shares some examples of working definitions we are using in discussing radical collaboration. 
Collaboration: Though collaboration is viewed as a familiar concept, it is a term that is often used to refer to activities that are not truly collaborative. Some definitions of collaborate include: to work jointly on an activity or project; ${ }^{2}$ to work jointly with others or together especially in an intellectual endeavor; ${ }^{3}$ and from late Latin "collaboratus," past participle of "collaborare" to labor together, from Latin "com-" + "laborare" to labor.4 In this discussion, collaboration means: "to rely on others to do agreed upon things for or in concert with you and to be relied upon to do agreed upon things for or in concert with others." 5

Identifying what something is not can be an effective way to build understanding. Collaboration is not:

- letting a purported partner know what you did after you did it;

- basic information sharing that has no measurable impact on the sharer or receiver of the information; or

- simply allowing someone to be present or to observe without providing them with the means to inform and influence what happens as a result of an interaction.

The most productive and sustainable collaborations begin with common interests and responsibilities, by defining problem statements together. Being able to rely upon others results from accrued trust based on the perceived reliability of partners.

Trust becomes possible when member expectations and roles are defined through iterative discussion and lessons learned, When a new collaboration starts, members bring their individual and often idiosyncratic definitions with them, often unaware that others may understand these terms very differently. what went well and what might be better next time. It is not possible to achieve success if we do not know what it looks like. Collaborations become sustainable when a critical mass of a community's members 
perceive that there is a track for reliability, which becomes an incentive for continuing to collaborate. Members-sometimes subsets-of other communities and domains, form a new community. A new community thrives by devoting time to getting acquainted.

Community: Communities may be formal or informal; large or small; short-lived (for example, for the life of a project or initiative) or ongoing (for example, the growing and cumulative group of people engaged in digital practice); or loosely or tightly integrated because community affiliations depend on context. In this discussion, community refers to: "a feeling of fellowship with others, as a result of sharing common attitudes, interests, and goals." ${ }^{6}$ Examples help with shared awareness and understanding. Examples of my communities include: the archival community, the digital preservation community, the digital practice community, the LGBTQIA community, dog parents, and many others.

Digital practice: When we talk about digital practice, what do we mean? The working definition of digital practice that I use is: "to continually work [using digital technology] to bring content and lessons from the past for the benefit of the present on behalf of the future." It is important to emphasize that good digital practice is cumulative, iterative, responsive to organizational and technological change, inclusive, and open. Whenever we look back through time, we increasingly perceive past practices and other forms of norms as quaint-that is a natural occurrence as our communities advance and as we become more familiar with available tools and technologies. That does not mean we cannot not learn from past practices, only that we should be thoughtful and kind in looking back. Not only can we learn from the past, but good practice dictates that we take the time to understand and bring lessons forward, many of which continue to apply to any digital content. Neglecting to learn from the past-from our own domains as well as others-wastes time, opportunities, and our limited resources. 
Radical: We are using "radical" in the sense of favoring extreme change in existing practices. See the next section for a discussion of radical collaboration.

\section{What Makes Collaboration Radical?}

A useful path for answering this question begins with a concept called radical candor, defined and popularized by Kim Scott. ${ }^{8}$ Scott explains the term using two dimensions: "care personally" and "challenge directly." Radical candor succeeds at both of these dimensions and represents the ideal for providing feedback. When you engage in radical candor, you tell people what you believe they need to hear, not want to hear, in a way that allows them to address your feedback, and in the best of circumstances, to grow or advance.

Here is a brief overview of the other three quadrants that illustrate how you should avoid providing feedback:

- Obnoxious aggression results from challenging directly and not caring personally, an approach that may succeed in dominating others, but also alienates them;

- Manipulative insincerity fails on both dimensions by neither caring about nor challenging someone to achieve what you want at their expense; and

- Ruinous empathy happens when people care, but fail to challenge, a version of killing people with kindness that cannot result in progress. 


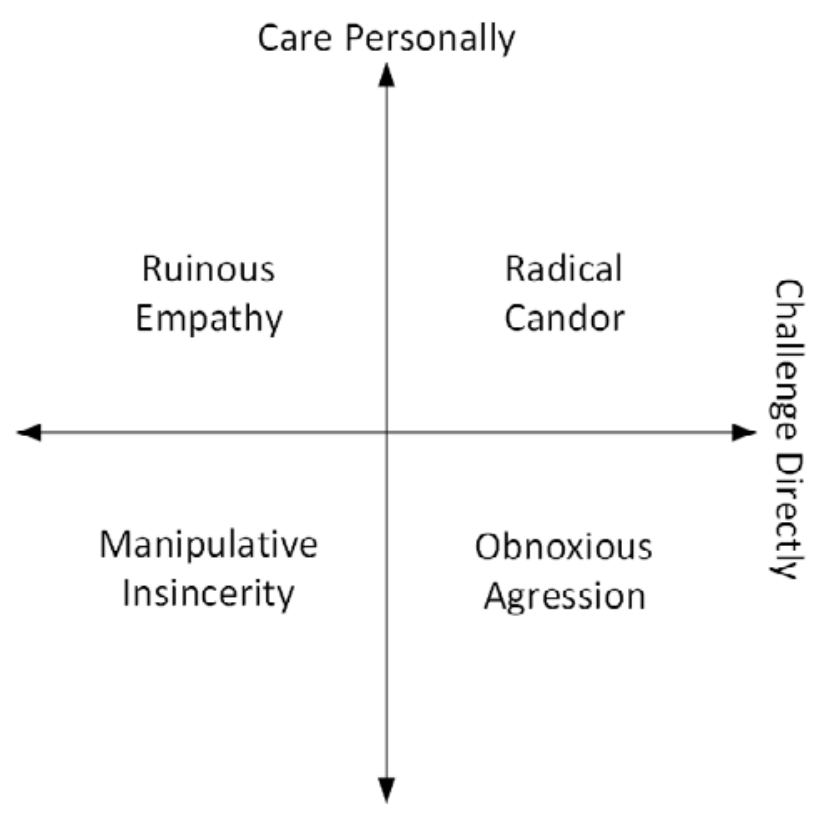

Figure 1. Radical Candor by Kim Scott

When I learned about radical candor, radical collaboration became a natural corollary, an essential element of being able to collaborate effectively. Adapting the radical candor grid (Figure 1) identifies and calls out interactions that are not collaborative and are insufficient for collaboration. In the dimensions of the radical collaboration grid (Figure 2), "care personally" becomes "commit communally," and "challenge directly" becomes "engage interactively." Radical collaboration is inclusive, involving commitment and effort by most or all members that are broadly representative of the various aspects of the common interests or problem. Radical collaboration does not mean standing back from or passively observing a community building effort, then expecting to control or influence the outcomes of that interaction. Like radical candor, radical collaboration embraces the two dimensions: commit communally and engage interactively. Radical collaboration represents the ideal for interacting with people to achieve common objectives, what collaboration should be and seldom is. When you engage in radical collaboration, you participate in an interaction of two or more people allowing the group to achieve and sustain outcomes that members could not individually, the resulting community flourishes-successes are visible and measurable, 
and people want to join. Here is a brief overview of the other three quadrants of radical collaboration that illustrate how you should avoid interacting with people:

- Dominant coordination may involve all or most of the members using dictatorial means that may control the direction, but limits the impact by failing to leverage the strengths of the whole;

- Exclusive interactions sacrifice the community by involving a small number of people (often two) for short-term gains at the expense of sustained community-wide action; and

- Passive sharing is an interaction that requires little effort and, though labeled collaboration, has the least impact and frustrates community building by being the antithesis of inclusive.

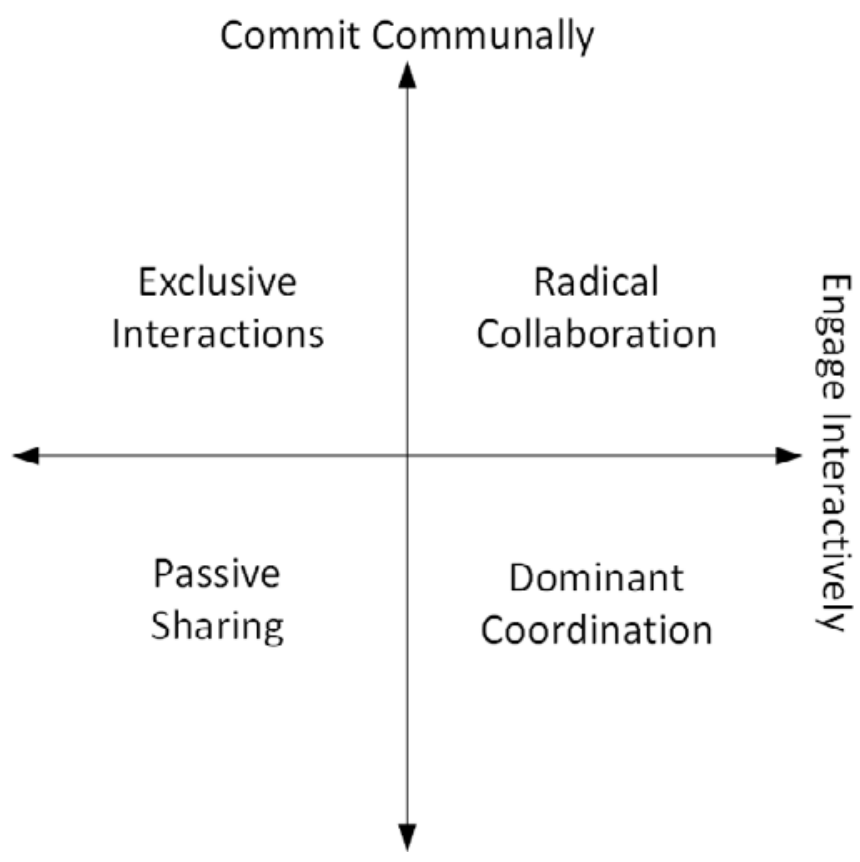

Figure 2. Radical Collaboration

Months after I shared the first version of the radical collaboration grid, I searched the internet for "radical collaboration" not expecting to find much, and discovered the radical collaboration movement. ${ }^{9}$ This version of radical collaboration comes from the business world and has a competitive focus as evidenced by one of their guiding quotes, "You 
can't compete externally, if you can't first collaborate internally." The discussion of radical collaboration in this issue of $R L I$ is about breaking down walls between domains, communities, and professions to build sustainable, inclusive communities that are able to solve problems together by leveraging cumulative strengths. Rather than focusing on individual organizations, which also has benefits, radical collaboration in this context focuses on developing communities that build on organizations.

\section{Coming Together}

A primary objective of radical collaboration is to be inclusive-to gather around a shared interest, responsibility, or problem, all of the skills, good practice, and resources, including human. In a new community space, the participants should come from across a range of domains and not be familiar with one another's missions, strengths, experiences, or norms. It is not possible to know the scope, the desired outcomes, timeframes, level of commitment, and other key factors in successful collaborations without coming together to discuss them.

The Inclusion Framework ${ }^{10}$ (Figure 3) assists with this objective by emphasizing aspects along the spectrum of inclusivity to consider for community efforts. Some facets of inclusion are increasingly familiar, for example, social and demographic, and some will need to become more familiar to bring our best efforts to emerging and evolving challenges for our cumulative communities, especially when technology plays a significant role in finding and sharing possible solutions. Professional inclusion is key to working across domains, understanding what everyone brings to discussions and problem-solving. Technical inclusion includes both the full range of technical skills that may be needed, and an acknowledgment that technology-the skills, the equipment, the training, the opportunity to gain experience-is not equally distributed, creating a have/havenot challenge that radical collaboration can help address. The terms technical and technological are often used interchangeably, a tendency 
that can increase technical exclusion. Technological tends to refer to computers, though technology is a much broader term than that. In digital practice, we all have technical expertise-a deep knowledge of techniques that require skill-though we may not all be well versed in the machines, tools, and know-how of computers. We all have something to bring to the table.

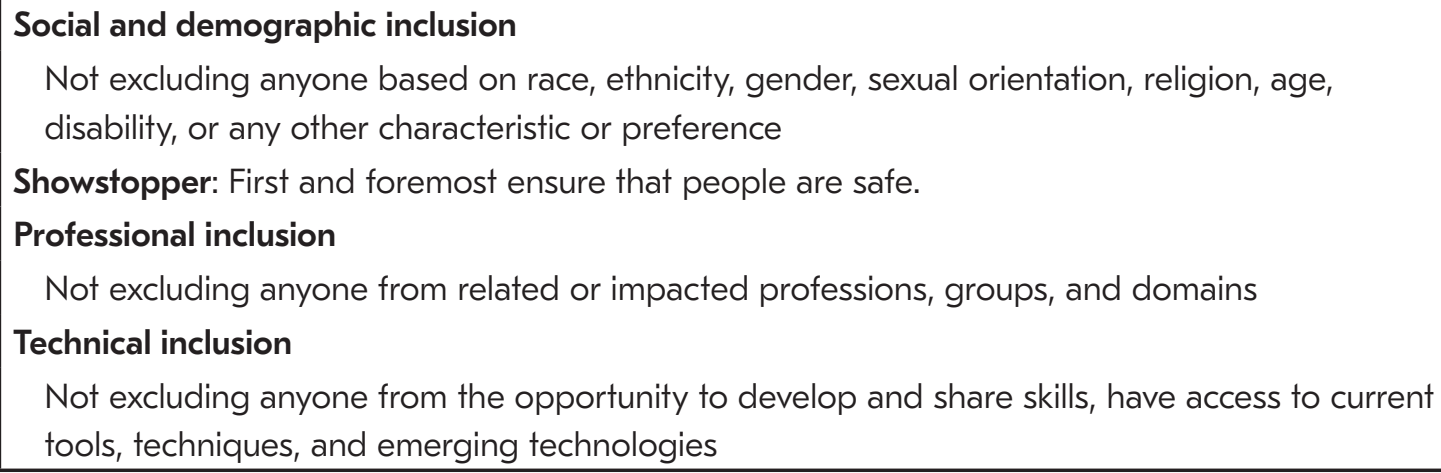

Figure 3. Inclusion Framework

We may believe that we are being as inclusive as possible in all of these ways, but intending and achieving can be a distance away from each other. Our own experience and expertise may limit our views and perspectives and reduce our ability to address new challenges without us realizing it. Radical collaboration is iterative and cumulative, including more people, skills, and knowledge as we better understand our shared problem spaces and discover the often untapped possibilities unlimited access to domains enables.

\section{Sharing the Table}

If we imagine good practice for digital practice taking place at an inclusive table that brings people together in shared spaces to solve mutual problems, we can begin to think about how to set that table. When we begin working on a new or less familiar problem, it is not possible to know the full extent of what inclusion could or should mean-we need to gather information and listen before convening. It make take some effort-discussion, sharing some working definitions, adjusting and aligning expectations-to develop an understanding of 
who might be most able to come together to address our current and emerging challenges. We often come together to work on problems, though we do not tend to reach across the boundaries of domains, professions, or organizations to tap the wealth of relevant skills. What could it look like if we did that?

As an example, the roundtable below is set for digital practice with research data management in mind. The listed domains and strengths of each are only examples. The beauty of a roundtable is that there is no

We may believe that we are being as inclusive as possible... but intending and achieving can be a distance away from each other. head-when we come to the roundtable, we should determine roles and responsibilities based on the nature of the problems and our cumulative needs as those evolve. People may come and go over the phases of a project; someone who convenes a group may not lead it. An inclusive roundtable enables us to come together and play to our strengths. Professional inclusion is like a trip to the candy store for engaging in good digital practice-who would we like to work with? Through an ongoing learning process and an open search for contributors, we will discover common interests, overlapping members, and intersecting objectives. A question we should ask sooner and more often is: who is not at the table and why? 


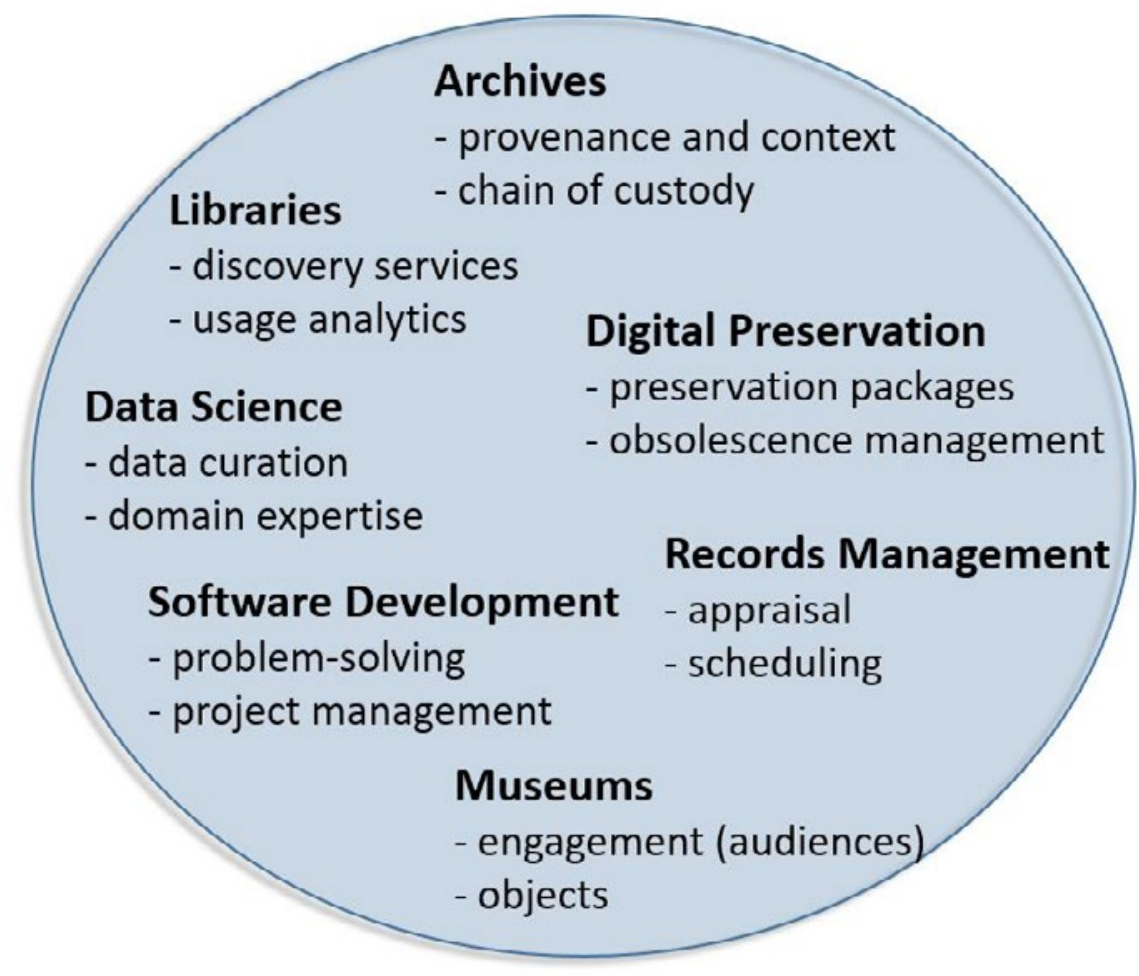

Figure 4. Roundtable for Digital Practice ${ }^{11}$

In practice, we cannot fit everyone who might need or want to be at the table, but we can be sure that the combination of people at the table and who have access to the table is inclusive, representative, and responsive.

\section{Emerging Distributed Digital Practice}

In part, what we are experiencing is a shift to an emerging generation of digital practice. Generations of practice reflect the problems each emerged to address. People working in teams within and across domains, organizations, and communities develop and share tools, techniques, skills, and experiences. As new technologies emerge, a new generation of practice will be needed that is suited to the new and evolved capabilities, needs, and gaps of that combination of technologies. Each new generation should build on previous 
generations. Right now, distributed digital practice is emerging that reflects advances in computer processing speeds, capacity, and storage. As a result, there is a lot of effort on artificial intelligence, machine learning, and related fields-areas that take advantage of those advances. We are always dealing with hybrid collections that are the results of multiple generations of digital practice. It is not that previous generations of practice are bad, only that the there is an increasing dissatisfaction with existing practice because it was not built to do what the new technologies require. Generations of practice follow generations of technology; a shift to distributed technology naturally leads to distributed practice.

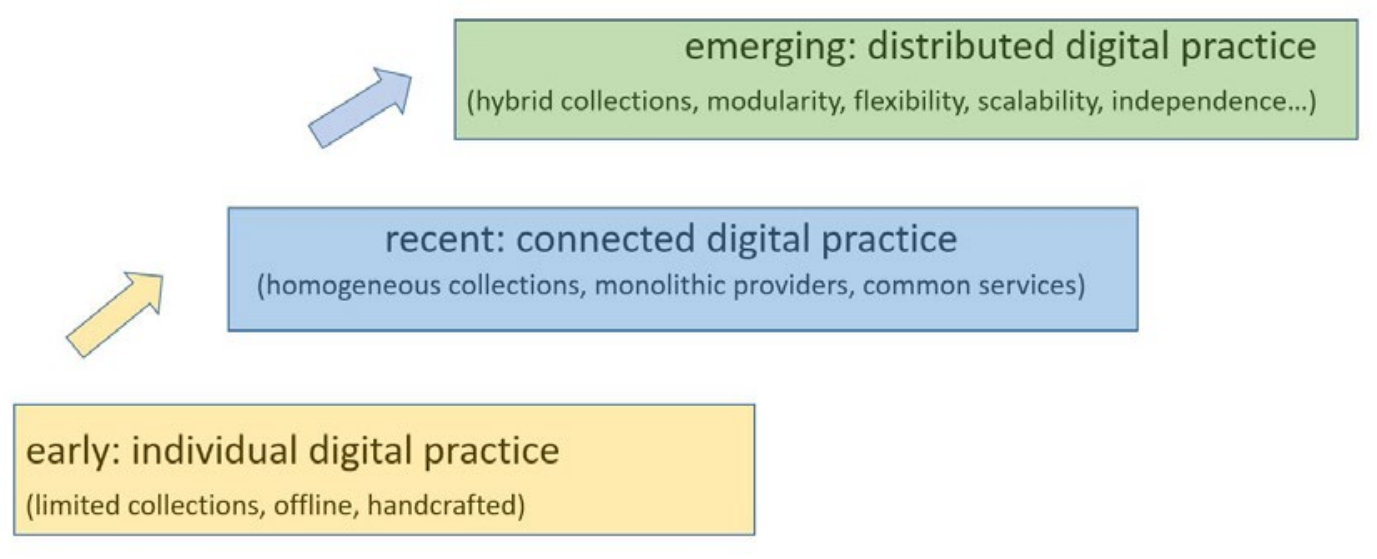

Figure 5. Generations of Digital Practice

The emergence of a new generation of digital practice is often full of tension and strife as people experience the emerging generation in different ways and at different paces based on interest, timing, and need, and as the need continues to engage in current practice. This can be frustrating and unproductive or it can be an ideal moment and opportunity to engage in radical collaboration, to become a learning community together. If we revisit the working definition of digital practice-"to continually work [using digital technology] to bring content and lessons from the past for the benefit of the present on behalf of the future"-we can extend it to become a working definition of distributed digital practice. The definition would continue: "achieved through radical collaboration across all domains that are 
interested, engaged, reliant upon, or willing to help to continually devise, implement, and improve solutions in response to ongoing technological change." An emerging combination of technologies transforms the ways in which content is created, how research is done, how we learn, and how knowledge is taught. Distributed digital practice, as we build it, will enable us to curate and preserve the results of this transformation and to leverage the capabilities to improve and advance our own practice. We cannot succeed at distributed digital practice if we do not embrace radical collaboration.

\section{Building (an Inclusive) Community}

We have organizational tools available from developing previous generations of digital practice that can help us become an inclusive community actively and successfully engaged in distributed digital practice. The stages of an organizational maturity model-a community being a type of organization-can help.

Common stages of organizational maturity model: ${ }^{12}$

1. Acknowledge: understanding that this is a local concern

2. Act: initiating projects

3. Consolidate: transitioning from projects to programs

4. Institutionalize: incorporating larger environment; rightsizing programs

5. Externalize: embracing inter-institutional collaboration and dependency

When we transition to a new generation of practice, the starting point is acknowledging that there is an unmet challenge as individuals, as organizations, as a community. This acknowledgment leads to the need and desire to act, generally in the form of a project-the number of distributed digital practice projects is increasing rapidly, for example, machine learning and artificial intelligence are everywhere. 
The transition from stage 2 to stage 3 for a community represents a particular challenge for inclusion because the skills are concentrated in a group of early adopters who are developing expertise in the skills needed for the emerging generation of practice. This concentration leads to exclusion, people who know and people who don't. This is the transition point our emerging distributed digital practice community is at-it is time for early adopters to carry on developing and advancing their expertise and it is time for popularizers to step forward, people who care about the objectives and whose skills include raising awareness, effective communication, and other means that expand community.

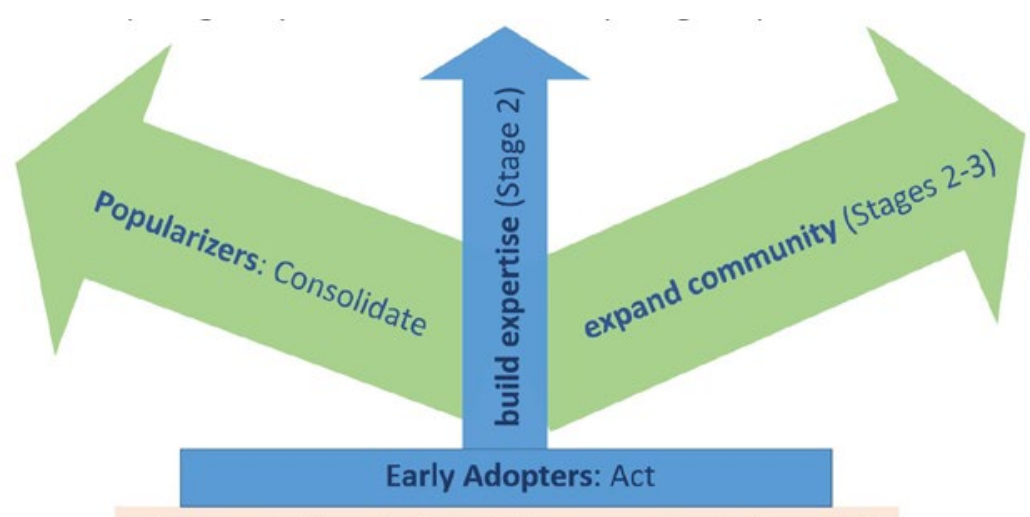

Pioneers: Acknowledge - initiate community (Stage 1)

Figure 6. Building Sustainable Programs for Communities ${ }^{13}$

The exhaustion caused by endless projects, a characteristic of stage 2 , eventually encourages organizations and individuals to develop more sustainable programmatic responses, first basic then increasingly advanced. Programs then use projects strategically to advance programs. More and more organizations have developed stage 4 programs for digital practice-we have a foundation and a growing community base for achieving distributed digital practice, building on what we have learned. Distributed digital practice requires working across domains, institutions, and communities. We will be discovering what stage 5 that intentionally includes radical collaboration will look like as we transition to distributed digital practice. 


\section{Some Guiding Principles for Radical Collaboration}

This introduction lays out the core concepts around radical collaboration and provides some context for the contributions that follow in this issue of $R L I$.

These are some considerations in thinking about how we begin to engage in radical collaboration:

- Raise awareness through open discussion-listen and assume good intent; use inclusive terms (for example, digital practice) and adjust.

- Be aware of using our own lens and our cumulative progress in viewing our past-it's like saying, "Those dratted people in the '90s refused to use social media!" before that was possible.

- Balance advocacy and inquiry-determine when to make your case, and when to listen and learn to deepen your awareness and understanding

- Continue from now-facing forward (informed by lessons learned)-look for opportunities-expect the unexpected.

The concluding section of this issue of $R L I$ will build on this starting point to help envision what radical collaboration will look like.

\section{Endnotes}

1. I defined and explored "radical collaboration" as a concept in a series of presentations in 2017 and 2018, including "Collaborating across Communities: Leveraging Our Strengths for Sustainable Programs and Services" (13th International Digital Curation Conference, Barcelona, Spain, February 21, 2018), http://www.dcc. ac.uk/sites/default/files/documents/IDCC18/PresentationsIDCC18/ NMcGovern_IDCC2018.pdf. 
2. Oxford Living Dictionaries, s.v. "collaborate (v.)," accessed November 29, 2018, https://en.oxforddictionaries.com/definition/collaborate.

3. Merriam-Webster, s.v. “collaborate (v.)," accessed November 27, 2018, https://www.merriam-webster.com/dictionary/collaborate.

4. Merriam-Webster, s.v. "collaborate (v.)."

5. Nancy Y. McGovern, "Presidential Address" (Society of American Archivists Annual Meeting, Portland, Oregon, July 27, 2017).

6. Google Dictionary, s.v. "community (n.)," accessed November 27, 2018, https://www.google.com/search?q=dictionary\%20 google \#dobs=community.

7. McGovern, "Presidential Address.”

8. A brief and engaging video of Kim Scott defining radical candor that provides a great overview of the concept is available online: "INBOUND Bold Talks: Kim Scott 'Radical Candor'," January 20, 2017, 14:48, https://www.youtube.com/watch?v=yj9GLeNCgm4.

9. Example of the radical collaboration movement in industry: Radical Collaboration website, accessed November 27, 2018, http://www. radicalcollaboration.com/.

10. McGovern, "Collaborating across Communities: Leveraging Our Strengths for Sustainable Programs and Services” introduced the Inclusion Framework.

11. This paper introduced the roundtable for digital practice and includes additional information and context: Nancy Y. McGovern, "Archives, History, and Technology: Prologue and Possibilities for SAA and the Archival Community," American Archivist 81, no. 1 (Spring/Summer 2018): 9-2.

12. Anne R. Kenney and Nancy Y. McGovern, "The Five Organizational Stages of Digital Preservation," in Digital Libraries: A Vision for the 21st Century: A Festschrift in Honor of Wendy Lougee on the Occasion of Her Departure from the University of Michigan, ed. Patricia Hodges, 
Mark Sandler, Maria Bonn, and John Price Wilkin, SPO Scholarly Monograph Series (Ann Arbor, Michigan: The Scholarly Publishing Office, The University of Michigan, University Library, 2003), https:// doi.org/10.3998/spobooks.bbv9812.0001.001.

13. McGovern, "Archives, History, and Technology: Prologue and Possibilities for SAA and the Archival Community."

(C) 2018 Nancy Y. McGovern

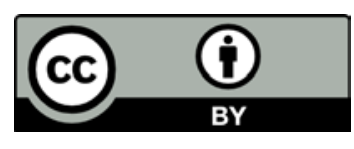

This article is licensed under a Creative Commons Attribution 4.0 International License. To view a copy of this license, visit https:// creativecommons.org/licenses/by/4.0/.

To cite this article: Nancy Y. McGovern. "Radical Collaboration and Research Data Management: An Introduction.” Research Library Issues, no. 296 (2018): 6-22. https://doi.org/10.29242/rli.296.2. 


\title{
The Radical Collaboration of RDA and What It Means for Developing Institutional Data Management Services
}

\begin{abstract}
Amy Nurnberger, Program Head, Data Management Services, MIT Libraries, and Co-Chair, Research Data Alliance Organisational Advisory Board
\end{abstract}

The Research Data Alliance (RDA) is an organization dedicated to reducing barriers to data sharing and exchange. ${ }^{1}$ While there are many technical barriers that must still be surmounted, it is a core principle of RDA that technical impediments are not the only ones. Often the more challenging barriers are the less visible social roadblocks and those blockades constructed at the intersections of the technical and the social. In my experience in developing and working in institutional data management services, these services are also dedicated to easing the way to data sharing and are likewise subject to a similar set of barriers. The connections between how RDA works, how data management services develop in institutions, and how radical collaboration happens may map out a route to more successful service development practices.

In my personal experience as a member of RDA and co-chair of multiple subgroups, the primary, yet less-noted, obstacles that RDA removes are those between the diverse people who work with or care about research data in some fashion. Whether you are an information technologist, archivist, researcher, scientist, librarian, professor, program or project

RDA brings people together across experiences, roles, and disciplines in the common cause of sharing research data in a responsible manner that supports the scholarly record of research. manager, chief corporate officer, managing director, policy developer or manager, funder, other data professional, otherwise impacted by data, or some magical unicorn-like combination thereof, you will find like minds at RDA in 
conversation and keeping company with one another. You will find a similar roster of characters as stakeholders in developing institutional data management services.

RDA brings people together across experiences, roles, and disciplines in the common cause of sharing research data in a responsible manner that supports the scholarly record of research. One of RDA's main contributions is the establishment, support, and maintenance of a space where people collaborate to address some of society's grand challenges. As of July 2018, RDA has 93 groups, ${ }^{2}$ which have collectively produced over 24 recommendations and outputs, which are "the technical and social infrastructure solutions enabling data sharing, exchange, and interoperability." ${ }^{3}$ These products range from Machine Actionable Policy Templates, ${ }^{4}$ an information and communications technology (ICT) technical specification, to Repository Audit and Certification Catalogues, ${ }^{5}$ a harmonized procedure for certifying repositories, to Wheat Data Interoperability Guidelines, Ontologies and User Cases, ${ }^{6}$ an aid to researchers in organizing and communicating their data, to 23 Things: Libraries for Research Data, ${ }^{7}$ an overview of research data management resources and tools for librarians. The recommendations and outputs have been adopted or implemented by over 60 organizations, including universities, research centers, repositories, international research efforts, and more. The broad range of the challenges that RDA members address, the solutions they create, and the organizations that implement them speaks to the underlying success of RDA, creating the environs where radical collaboration can occur to address those challenges of research data.

Of course, not all of the current RDA groups, or the groups that have come and gone in the past, have been equally successful in developing solutions that reflect the full strength and participation of group members. Similarly, our institutions are often tasked with addressing society's grand challenges, and we see a comparable variability of success when it comes to developing local solutions for removing barriers to data sharing, in the form of institutional data management 
services. The intersections between RDA group formation, service development, and the concepts of radical collaboration offer interesting ground for exploring commonalities, differences, and possible roads to success that radical collaboration offers.

\section{The Evolution of Collaboration}

An important aspect of collaboration is its evolution. This is true of both RDA groups and institutionally based service development efforts, the differences being the available starting points and the supporting structures provided for the paths forward. Within RDA there is a process for forming groups that often starts with an informal gathering termed a "Birds of a Feather" (BoF), where people with a shared need or idea meet to talk through whether there seems to be sufficient expressed community interest to start coalescing around a shared end goal.

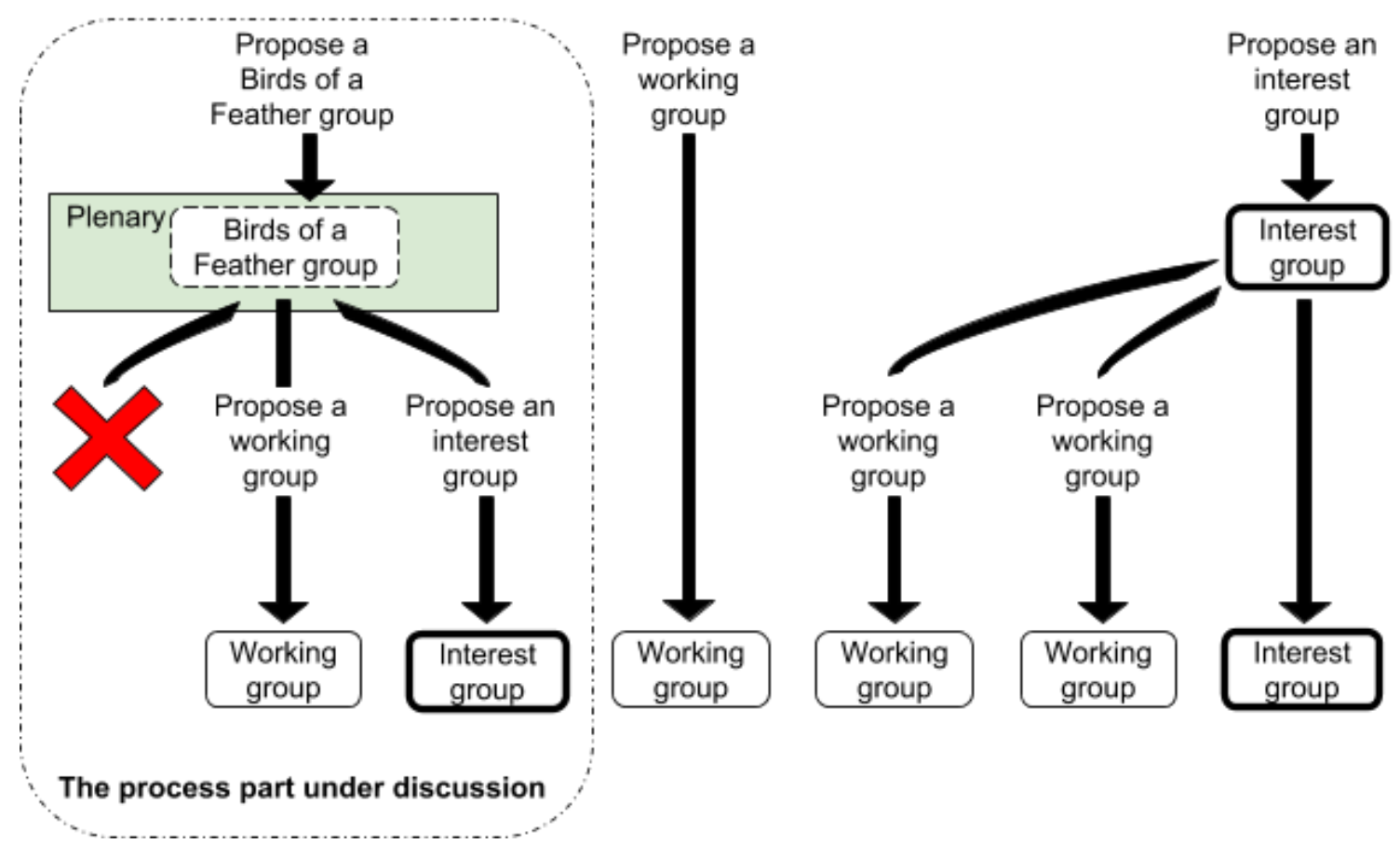

Figure 1: How RDA working groups form

The interactions in these BoF meetings vary and account for most of the potential starting points for collaborations. The exception, which I 
have not encountered in RDA, is the situation that frequently shows up in institutional settings where groups are notified of charges to go forth and develop services or otherwise "do."

McGovern identifies interaction types in "Radical Collaboration and Research Data Management: An Introduction," ${ }^{8}$ as the quadrants of a matrix, and names them as Radical collaboration, Exclusive interaction, Dominant coordination, and Passive sharing. I have used these quadrants as a foundation, expanding particularly on the nuances of Passive sharing to more accurately represent the variety of starting points that then evolve into collaboration modes:

- Inadequate intersections is an interaction signified by lack of interaction; everyone is passive and there is little common ground or shared understanding.

- Notification presumes commonality of purpose but overlooks the necessity of building community through interaction, ultimately shortchanging the strengths and contributions of the potential community.

- Little listening occurs when people have committed to their idea, but not to the community, and have spoken but have not engaged interactively.

These six starting points provide the initial states for the evolution of potential collaboration.

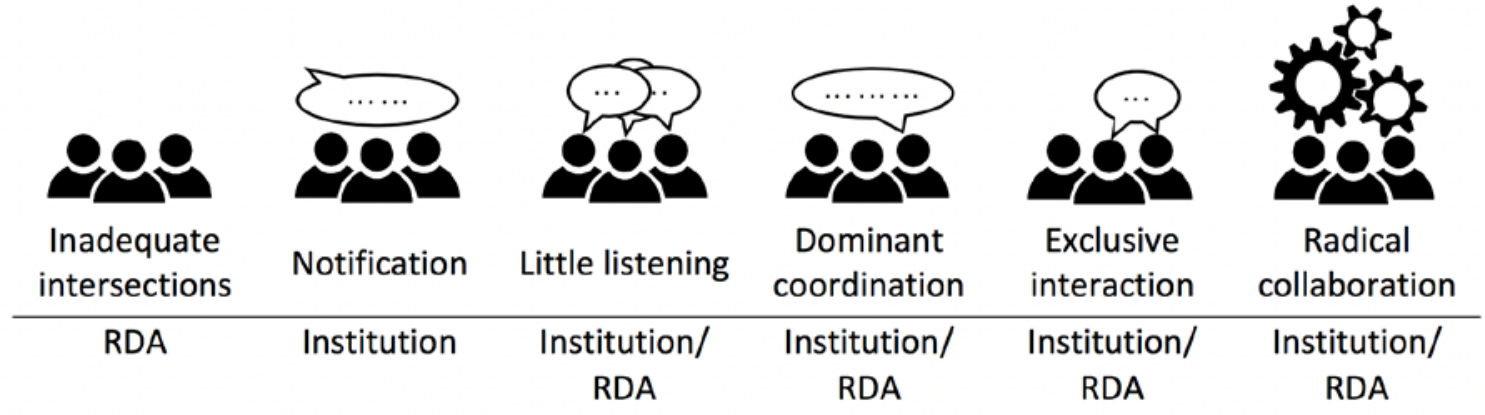

Figure 2: Starting points for potential collaboration by organization type 


\section{Encouraging Radical Collaboration}

Collaboration modes evolve from their starting points. In RDA, this evolution is helped toward the state of radical collaboration by the group proposal process, through which the Technical Advisory Board (TAB) reviews group membership and leadership, and recommends others who should be invited to sit at the table. This process supports balance, one of the core values of $\mathrm{RDA},{ }^{9}$ which is equivalent to the radical collaboration concept of having representative places set around the table. Radical collaboration is further encouraged in RDA through the adoption and implementation of other of its core values: openness, consensus, and harmonization. In addition, the communitydriven nature of RDA leaves little room for groups that are run in a style of Dominant coordination. ${ }^{10}$

Within an institutional setting, the starting points and motivations for collaboration are slightly different. In particular, groups formed in a Notification style or lacking community will to exist are still expected to perform. This creates a greater burden on both participants and leaders. A role equivalent to what TAB fulfills in the group proposal and refinement process of RDA is often difficult to coordinate at an institution, which may represent a more complex community, and where there is no single group similar to TAB. Lacking the strategic oversight of TAB or a similar group that is focused on inclusion, balance, and processes enabling representation, participants in an institutional setting must be self-conscious in considering with whom they are sharing a collaboration, who else should be involved, and how they will establish an environment that normalizes the behavioral expectations required for radical collaboration.

Institutional leadership also has responsibility in setting the stage for radical collaboration. A parallel to this is laid out in Manges et al.'s extension ${ }^{11}$ of Tuckman's group development model, ${ }^{12}$ where in the forming stage, leaders may engage in coordinating behaviors that encourage group success such as purposeful team selection, 
and facilitating team-identified goals and a team-developed shared mental model. Leaders may further promote radical collaboration by employing the principle of the roundtable and considering broadly who should be invited to it. In their facilitating practice, leaders may place special emphasis on the values of inclusivity and inquiry, which are part of the radical collaboration framework put forward by McGovern. ${ }^{13}$

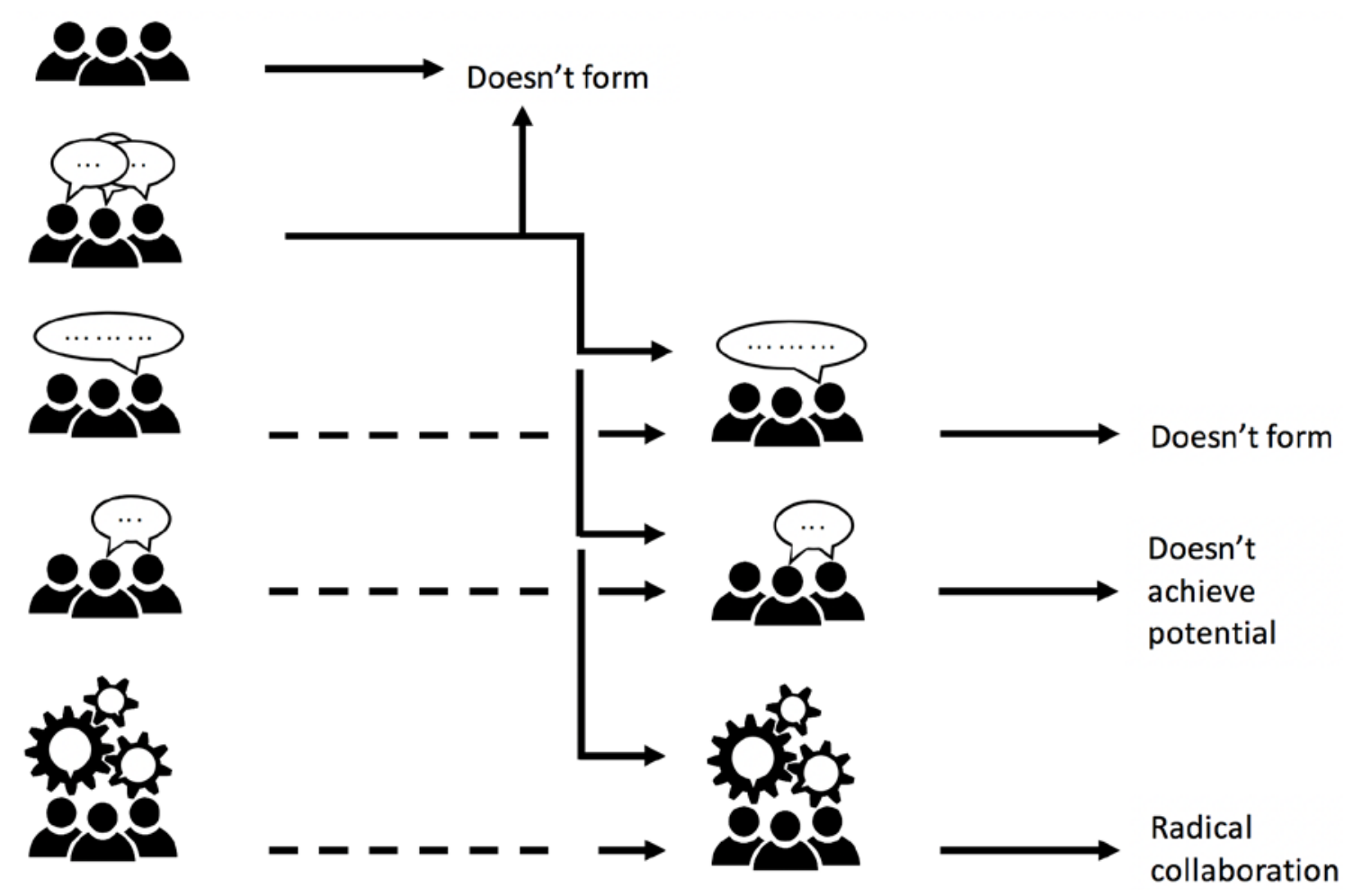

Figure 3: Evolution of RDA/community-driven collaboration modes

In both the RDA and institutional settings, groups that work well are ones where it evolves that experience is respected, differences are appreciated, and working together is considered an opportunity to learn, not to proselytize. Groups that don't achieve their potential are ones in which some subset of the participants arrives with a solution in hand, and they are unwilling to consider alternative solutions while other participants display an unwillingness to consider the offered solution in the problem space. This is potentially a case of Exclusive interactions, as elaborated by McGovern. ${ }^{14}$ Exclusive interactions can also be detected in how language is used: is it multifaceted, do people explain what a term means to them, is there an effort made to construct 
cross-understandings? Or is there that built understanding developed out of co-created working definitions, which McGovern ${ }^{15}$ points out as an effective tool for radical collaboration?

As a leader or participant in a group in any setting, it is necessary to be sensitive to the interaction types that are occurring and how collaboration modes are evolving. Language use both defines and betrays us. Listening to how a group speaks can reveal how they have defined themselves with the limits they have committed to work within, whether narrow or expansive. Equally, language affects how individuals are perceived in collaboration settings, and may betray our best intentions when it is assumed to indicate our implicit understandings and perspectives. We each have a responsibility within a group to listen with the assumption of good intentions and to speak in ways that can be heard. Coming to a shared use of language is a difficult and important part of forming shared goals, a shared mental model, and a shared commitment to engage in radical collaboration.

In building institutional data management services, language also has an important signaling effect. Given the wide variety of institutional groups that must work together to form a robust service,${ }^{16}$ it is rare that we will ever all mean the same thing when we use words like "repository" or "workflow" or even "data." Taking the time to work through assumptions and having a willingness to adapt understandings and language usage is imperative. Another way to term this is to deploy a caring curiosity: when you care enough to really figure out what it is an individual means and how they understand the challenge. It takes a level of confidence to accept spaces of ambiguity in this radical collaboration process and to work through them in a manner that is respectful and demonstrates hospitality to others' ideas.

\section{Bringing Everyone to the Table}

The metaphor of the table, particularly the roundtable, is useful here. If you are taking on the role of establishing a collaboration space, this is 
Coming together around [shared] motivations with a sense of generosity and hospitality, which is exemplified by openness, consensus, harmonization, and balance, creates the space for radical collaboration.... equivalent to hosting. A host is responsible for composing a guest list that is varied and inclusive. As the host of a roundtable, you don't sit at the head of it, but you do arrange the space so that guests feel welcome at it.

As a guest at a collaboration or a dinner party, you participate, but you don't dominate. Hospitality is demonstrated by the host and engaged with by the guests. Just as with dinner parties, so too with radical collaboration, the concept of hospitality is paramount.

It is in this generosity of spirit that radical collaboration is found, and that efforts in forming institutional services can learn from organizations like RDA that promote conscientious efforts of inclusion, balance, and openness. Despite differences in how efforts are initiated, there is a common motivation to solve problems, find solutions, and address grand challenges. Coming together around these motivations with a sense of generosity and hospitality, which is exemplified by openness, consensus, harmonization, and balance, creates the space for radical collaboration and may provide the setting for some truly extraordinary meals.

\section{Endnotes}

1. “Communication Kit: RDA in a Nutshell," Research Data Alliance, July 2018, https://rd-alliance.org/communication-kit.

2. "Communication Kit: RDA in a Nutshell," Research Data Alliance.

3. "Adoption Stories," Research Data Alliance, accessed December 4, 2018, https://www.rd-alliance.org/recommendations-outputs/ adoption-stories. 
4. Reagan Moore, Rainer Stotzka, Claudia Cacciari, and Petr Benedikt, "Practical Policy," B2SHARE website, EUDAT, December 22, 2016, http://dx.doi.org/10.15497/83E1B3F9-7E17-484A-A466-B3E5775121CC.

5. CoreTrustSeal (CTS), Core Trustworthy Data Repositories Requirements, DANS, 2016, https://doi.org/10.17026/dans-22n-gk35; and Lesley Rickards, Mary Vardigan, Michael Diepenbroek, Ingrid Dillo, Francoise Genova, Hervé L'Hours, Wim Hugo, et al., "DSA-WDS Partnership Working Group Catalogue of Common Procedures for Certification,” B2SHARE website, EUDAT, June 15, 2017, https://doi. org/10.15497/rda00019.

6. Esther Dzalé Yeumo, Richard Fulss, Michael Alaux, Sophie Aubin, Elizabeth Arnaud, Ute Baumann, Laurel Cooper, et al., "Wheat Data Interoperability Guidelines, Ontologies and User Cases: Recommendations from the RDA Wheat Data Interoperability Working Group,” B2SHARE website, EUDAT, June 1, 2017, http:// dx.doi.org/10.15497/RDA00018.

7. "23 Things: Libraries for Research Data (Supporting Output)," Research Data Alliance, accessed December 4, 2018, https://rd-alliance.org/group/libraries-research-data-ig/ outcomes/23-things-libraries-research-data-supporting-output.

8. Nancy Y. McGovern, "Radical Collaboration and Research Data Management: An Introduction," Research Library Issues, no. 296 (2018): 6-22, https://doi.org/10.29242/rli.296.2.

9. “Why Should You Become an RDA Member?” Research Data Alliance, accessed December 4, 2018, https://web.archive.org/ web/20171120070139/https://rd-alliance.org/get-involved/individualmembership.html.

10. McGovern, "Radical Collaboration and Research Data Management."

11. Kirstin Manges, Jill Scott-Cawiezell, and Marcia M. Ward, "Maximizing Team Performance: The Critical Role of the Nurse Leader," Nursing Forum 52, no. 1 (January 2017): 21-29, https://doi. org/10.1111/nuf.12161. 
12. Bruce W. Tuckman, "Developmental Sequence in Small Groups," Psychological Bulletin 63, no. 6 (1965): 384-399, http://dx.doi. org/10.1037/h0022100.

13. McGovern, "Radical Collaboration and Research Data Management."

14. McGovern, "Radical Collaboration and Research Data Management."

15. McGovern, "Radical Collaboration and Research Data Management."

16. Ricky Erway, Laurence Horton, Amy Nurnberger, Reid Otsuji, and Amy Rushing, Building Blocks: Laying the Foundation for a Research Data Management Program (Dublin, Ohio: OCLC Research, 2016), http://www.oclc.org/content/dam/research/publications/2016/ oclcresearch-data-management-building-blocks-2016.pdf.

(C) 2018 Amy Nurnberger

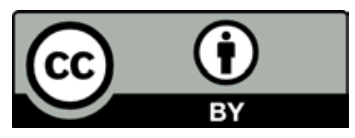

This article is licensed under a Creative Commons Attribution 4.0 International License. To view a copy of this license, visit https:// creativecommons.org/licenses/by/4.0/.

To cite this article: Amy Nurnberger. "The Radical Collaboration of RDA and What It Means for Developing Institutional Data Management Services.” Research Library Issues, no. 296 (2018): 23-32. https://doi.org/10.29242/rli.296.3. 


\section{Archives and Data Management: The Purdue Story}

Carly Dearborn, Digital Preservation and Electronic Records Archivist, Purdue University Libraries

Purdue University archivists were involved in some of the earliest discussions on campus around data management, thanks to the vision of former dean of libraries, James Mullins. When Mullins first began as dean in the early 2000s, he toured campus to find out how the libraries could meet the needs of campus departments, faculty, and students. Data management was a need quickly identified by the chief information officer at the time; however, faculty and department heads struggled to see how the libraries could help with data. They viewed the library as a place where ideas and research were shared openly and freely, often unattractive concepts to research scientists prior to national data-sharing initiatives. Hearing this, Mullins realized that the archives was especially equipped to handle the concerns of these researchers. Archivists are specifically trained to handle sensitive information and work with donors from a variety of disciplinary and professional backgrounds who may need portions of their collections restricted or embargoed for personal, proprietary, or security reasons. ${ }^{1}$ Furthermore, archivists have always been involved at every stage of the research process-from data collection to preservation and reuseand are familiar with raw data (even if that data has historically been analog) and its challenges. ${ }^{2}$

After Dean Mullins identified data management as a space where the libraries could add value, Purdue established a series of committees to think through the issue of data management at an institutional level. These committees included librarians, computer engineers, IT professionals, and domain scientists. Conversations were led by the vice president for research, and chaired by the dean of libraries and vice president for information technology and research, a trio that would oversee the creation of the Purdue University Research Repository (PURR) and make up the PURR Steering Committee. In 2010, the steering committee created the PURR Working Group to 
define and deploy the repository concept using the locally developed HUBzero software. ${ }^{3}$ The university archivist was a member of this working group along with other librarians, IT professionals, and domain scientists.

PURR was created to be a research and data management tool for Purdue researchers and their collaborators. It is currently the official data repository of the university. PURR now provides researchers with the tools to meet evolving

The success of these and other collaborations at Purdue Libraries is directly related to an administratively supported environment of experimentation data management and sharing requirements and a platform to seek help from their subject specialist librarian. PURR also provides a workspace for researchers to collaborate with their colleagues and an online publishing platform to

ultimately provide access to data. PURR publishes data sets with digital object identifiers (DOIs), which make it easier for other researchers to cite published data. Finally, PURR also provides preservation support for deposited data for up to 10 years-at which point the data set will go under review as would any other library collection.

After the PURR Working Group identified the requirements to create a repository and a service model, they put together a new team from the libraries to develop the platform's functionality and preservation infrastructure. This team includes librarians, a repository specialist, a programmer, a data curator, and an archivist. All still actively work together on the repository to maintain content, develop new features and improve user experience. ${ }^{4}$

The early collaborative initiatives between the libraries and its campus partners, and within the libraries amongst archivists, librarians, and IT professionals still inform collaborative work today. Outside of involvement in PURR, for example, archivists frequently collaborate 
with data librarians around data management instruction. Data management is still a growing need among graduate students and even undergraduate students. The libraries increasingly offer for-credit coursework in this area around campus. It can be challenging to talk about data management without speaking in hypotheticals. "If you don't have a file-naming convention, $\mathrm{X}$ might happen." "If you fail to export your data in this format, Y could occur." It is difficult to teach the necessity of data management to those who have never experienced the devastation of poor data management. This is where Purdue archivists come in. Using teaching data sets drawn from actual donated data sets, archivists join data librarians in classes to demonstrate what poor data management looks like at the end of the research life cycle and how it affects reuse of the data.

Data management is often taught in the context of a research life cycle; however, preservation is still approached as an afterthought or a step to take at the end of a research project. Involving archivists and their expertise in data management instruction can demonstrate how preservation informs good data management practices at the outset. Collaborations at Purdue in this area have resulted in additional workshops and documentation to help students (and faculty) better prepare their While data management is certainly a space where archivists belong, it does not mean the sense of belongingness comes easily. data for long-term preservation or access. The success of these and other collaborations at Purdue Libraries is directly related to an administratively supported environment of experimentation.

More and more institutions are enveloping archivists into their data management services. While data management is certainly a space where archivists belong, it does not mean the sense of belongingness comes easily. Still, it is important to remember that everyone is struggling with tough issues in the area of data management and 
the perspective of an archivist can have a lot of impact in how a preservation strategy is developed or how repository services should support researchers. Purdue Libraries certainly is not done grappling with difficult data management issues, but the diverse makeup of the team makes some of the problems appear a little less daunting.

\section{Endnotes}

1. James L. Mullins, personal communication, July 9, 2015.

2. James L. Mullins, "Bringing Librarianship to E-Science," College Et Research Libraries 70, no. 3 (May 2009): 212-213, https://doi. org/10.5860/0700212.

3. Michael Witt, "Co-Designing, Co-Developing, and Co-Implementing an Institutional Data Repository Service,” Journal of Library Administration 52, no. 2 (2012): 172-188, https://doi.org/10.1080/01930 826.2012.655607.

4. “The PURR Team,” Purdue University Research Repository, accessed December 14, 2018, https://purr.purdue.edu/team.

(C) 2018 Carly Dearborn

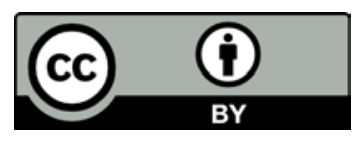

This article is licensed under a Creative Commons Attribution 4.0 International License. To view a copy of this license, visit https:// creativecommons.org/licenses/by/4.0/.

To cite this article: Carly Dearborn. "Archives and Data Management: The Purdue Story.” Research Library Issues, no. 296 (2018): 33-36. https://doi.org/10.29242/rli.296.4. 


\section{Barriers to Collaboration: Lessons Learned from the Data Curation Network}

Lisa R. Johnston, Research Data Management/Curation Lead and CoDirector of the University Digital Conservancy, University of Minnesota Libraries, and Principal Investigator of the Data Curation Network Project

There are many barriers that prevent us from actively and equitably collaborating in meaningful ways. When we launched the crossinstitutional Data Curation Network (DCN) project, ${ }^{1}$ our team took conscious steps toward seeking out those barriers and working to find ways to overcome them. I will present those barriers here and note some ways that we are attempting to overcome our obstacles.

First, a bit of background on our project. Our vision for the Data Curation Network is to ensure that researchers, when faced with a growing number of requirements to ethically share their research data, are preparing and archiving their data in ways that make it findable, accessible, interoperable, and reusable (FAIR). Data curation activities-such as quality assurance, metadata/documentation creation, code review, and file

The Data Curation Network project brings together the perspectives of research data librarians, academic library administrators, and domain subject experts from academic libraries and general-purpose or disciplinary data repositories. transformations-support FAIR data publishing and sharing activities. But data curation can be costly, requiring advanced curation practices, specific technical competencies, and relevant subject expertise. For multidisciplinary institutions and nonprofit data repositories, the sheer range of data curation expertise required to perform these services well is an enormous challenge. The DCN takes a collective approach to data curation. By sharing our expert data curation staff across DCN partner institutions, we enable ourselves to collectively, and more effectively, curate a wider variety of data types (for example, discipline, file format, 
etc.) beyond what any single institution might offer alone.

The Data Curation Network project brings together the perspectives of research data librarians, academic library administrators, and domain subject experts from academic libraries and general-purpose or disciplinary data repositories. Our project began in 2016 with six partners and funding from the Alfred P. Sloan Foundation, and has since grown to include eight partner institutions including the University of Minnesota (lead), Cornell University, Dryad Data Repository, Duke University, Johns Hopkins University, Penn State University, the University of Illinois, and the University of Michigan.

Curation staff are the "human layer" in the repository technology stack who bring the knowledge and software expertise necessary for reviewing incoming submissions to ensure that the data stand up to the test of time and are optimized for reuse. We do this several ways. First, the DCN creates a platform for partner institutions to share our curation staff using a coordinated workflow that connects data sets to the appropriate expert for that particular data type (for example, GIS data, 3-D images, simulation data, etc.). Second, the DCN provides a community for professional data curators. By sharing tools, providing a pipeline for training data curators, and Curation staff are the 'human layer' in the repository technology stack who bring the knowledge and software expertise necessary for reviewing incoming submissions to ensure that the data stand up to the test of time and are optimized for reuse. promoting data curation practices across the profession, the Data Curation Network aims to enrich capacities for data curation writ large. Third, the goal for the DCN will be to offer sustainable services and access to data curation expertise to end-users (researchers, libraries, journals, etc.) when none exist locally, for rare or infrequent data types, or in times of staff transition. 
To confront the challenges of collaboration, at the onset of our project we identified some specific barriers that might keep us from moving together toward a shared vision. We revisit these barriers annually and consider ways to reduce or eliminate these barriers. Some of the challenges that our project has faced include the following:

- Institutional priorities and culture. Each institution has different goals and priorities for how they approach data services. Institutional competition and internal competition (for example, tech transfer office goals at odds with library repository mission) could prevent DCN collaboration. Multi-institutional collaborations must deal with different institutional and local cultures.

- Site visits are planned at each member institution to discuss the project goals and outcomes with institution administration.

- Unvoiced concerns. Are we doing a good job at onboarding new DCN members? Are we building curator buy-in? Or creating opportunities to voice dissenting opinions?

- Regular in-person meetings have been one way to bring everyone in the DCN together. At these events we encourage multiple communication methods (for example, writing anonymous feedback and leaving it on the "ideas" table).

- Indeterminable or unknown value proposition. There is scant market research or literature to show that curated data are more valuable to researchers. What if our efforts are not valued or not well communicated? What if the costs outweigh the value? Demand for data curation is low, but metrics fail to tell the whole story.

- Our research agenda includes white papers describing the value of data curation to funders and stakeholders and documenting the cost savings of collaborative data curation.

- Complex and evolving ecosystem. Data sharing requirements and norms are in flux. Data curation is only part of a larger 
conversation about data sharing. Norms and best practices of curation are still forming.

- An early effort in our project was to research and document a shared glossary of data curation terms. ${ }^{2}$

- Challenges of practical network design. There is a tendency to over-engineer and create complex workflows. On the other hand, not everyone will "see themselves" in a more general workflow. There is a need to find balance.

- Developing a framework for shared work is changing. Our goals have been to not change how local institutions do data curation, but to keep the DCN workflow modular and allow institutions to decide locally how to best incorporate a shared staffing network. There have been many trial-and-error opportunities.

- Antiquated and limited view of libraries. Libraries face skepticism about having a role in data services at all. Some curators don't want to "criticize" researchers' data.

- Our planning phase spent a considerable amount of time holding focus group interviews with researchers to understand what data curation activities they find important and where our project could make the most impact. ${ }^{3}$

- No sustainable funding model. It is challenging to find and secure sustainable funding in an age of austerity. Within the cacophony of data projects and "membership fatigue"-being heard is hard.

- In our current phase we aim to engage a sustainability consultant to help navigate these issues.

- Easier to do it yourself. Library work is often built around relationships. If we rely on others to perform complex data consultations with local researchers, what opportunities for strengthening relationships are lost? It may be better, easier (or perceived as such) to do all curation work locally.

- A strong lesson learned from this project has been to keep 
local control over how and when to engage support from the network.

- All communication to local researchers will be mediated by a local curator so that connections can be strengthened and maintained.

- Transparency. How do we communicate what we are doing with our local campus? What if we don't tell researchers that external staff are curating data? Do we lose trust? (Do they know when using $24 \times 7$ chat services that these are done by libraries in different time zones?)

- This is an area we will be closely watching and assessing in our implementation phase over the coming year.

- Unbalanced workloads. Collaboration can mean more work for overburdened staff. How much local time/effort can be devoted to working on "someone else's" data? Participating institutions are at different places in their curation services (and expertise); at home institutions, what happens when one partner overuses shared resources?

- A grant project model will protect us in some ways (for example, staff have a dedicated amount of time to spend on the project and we will use project management software to help us keep track). But maybe we will need to let go, be more flexible. 


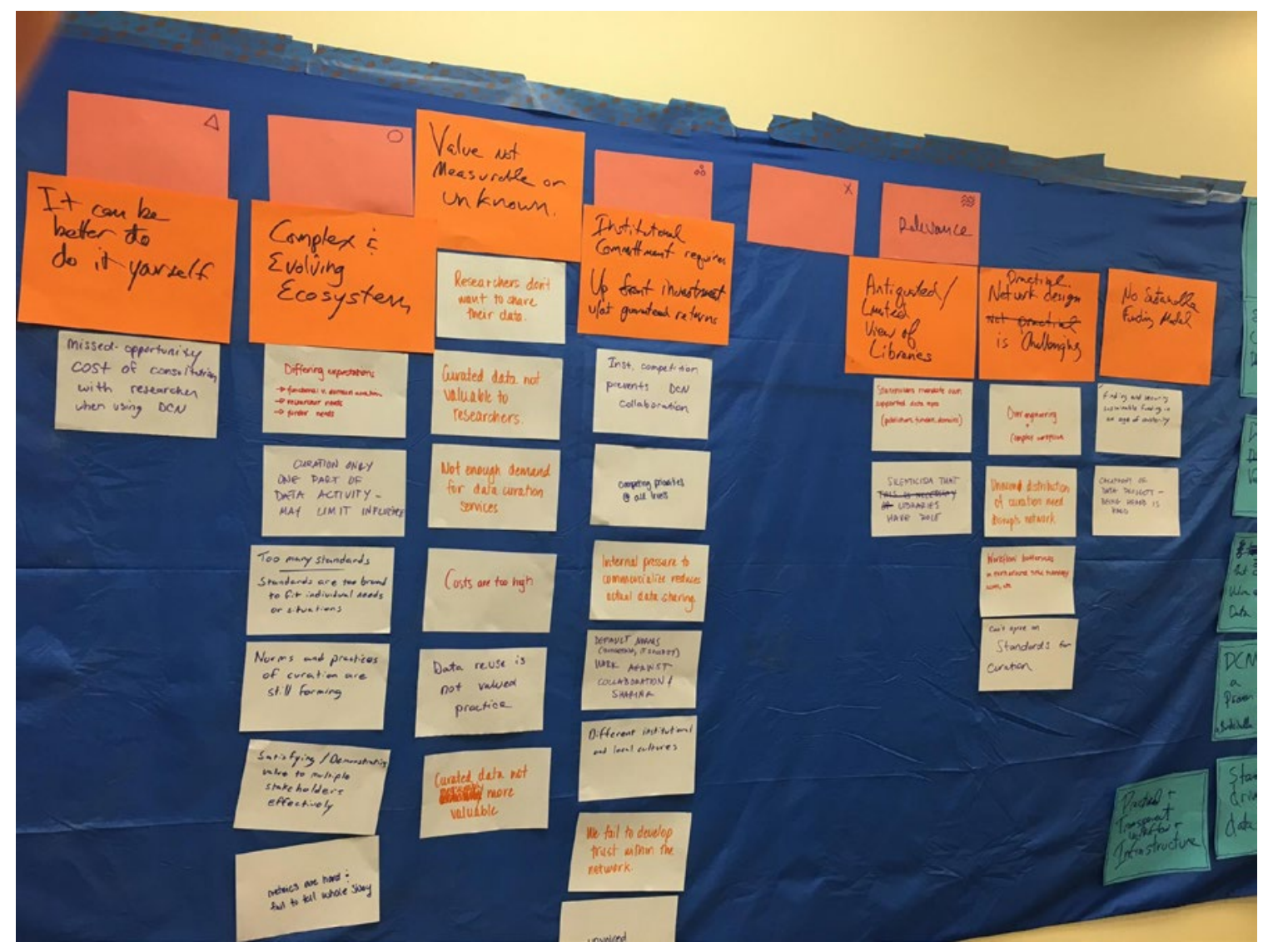

At the June 2016 kickoff meeting of the Data Curation Network, the team was led by a team collaboration expert to envision the goals for the project and to acknowledge the potential barriers. Notes from this meeting are published online. ${ }^{4}$

\section{Endnotes}

1. Data Curation Network website, accessed December 5, 2018, http:// datacurationnetwork.org.

2. Lisa R. Johnston, Jake Carlson, Cynthia Hudson-Vitale, Heidi Imker, Wendy Kozlowski, Robert Olendorf, and Claire Stewart, Definitions of Data Curation Activities used by the Data Curation Network, October 2016, retrieved from University of Minnesota Digital Conservancy, http://hdl.handle.net/11299/188638.

3. Lisa R. Johnston, Jake Carlson, Cynthia Hudson-Vitale, Heidi Imker, Wendy Kozlowski, Robert Olendorf, and Claire Stewart, "How Important is Data Curation? Gaps and Opportunities for Academic 
Libraries," Journal of Librarianship and Scholarly Communication 6, no. 1 (2018), http://doi.org/10.7710/2162-3309.2198.

4. Lisa R. Johnston, Jake Carlson, Cynthia Hudson-Vitale, Heidi Imker, Wendy Kozlowski, Robert Olendorf, and Claire Stewart, DCN Team Kick-off Meeting Outputs: Vision, Barriers, Metrics, and Strategic Directions, July 2016, retrieved from University of Minnesota Digital Conservancy, http://hdl.handle.net/11299/188637.

(C) 2018 Lisa R. Johnston

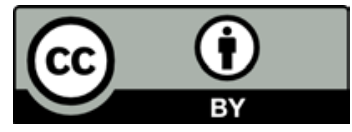

This article is licensed under a Creative Commons Attribution 4.0 International License. To view a copy of this license, visit https:// creativecommons.org/licenses/by/4.0/.

To cite this article: Lisa R. Johnston. "Barriers to Collaboration: Lessons Learned from the Data Curation Network." Research Library Issues, no. 296 (2018): 37-43. https://doi.org/10.29242/rli.296.5. 


\section{What is Open Science, and How Can Radical Collaboration Facilitate It?}

Megan Potterbusch, Data Services Librarian, The George Washington University

Open science is a multi-faceted movement serving as a goal and a motivation for many stakeholders, from researchers to information professionals and from funders to the general public. Aspects of open science include: open sharing of research materials such as data and code, collaborative research platforms, crowdsourcing platforms, blogs, open peer review, open educational resources, altmetrics, and more. These diverse aspects can be classified into schools of thought and are emphasized by members of various open-focused communities to different degrees (from intense belief to neutral to opposition in some cases). Regardless of the differences in views between diverse communities and differences in aspects or approaches, each of these forms of open science allows for additional levels of understanding, participation, or both by people external to the group producing the science.

In my work as a data services librarian, I serve the current needs of the research community, specific individual researchers, and students, and I support the anticipated needs of future researchers. In this way I must intersect between traditional "librarianship" and "archives" as

When working on a project designed to support a heterogeneous community... each collaborator's expertise and knowledge contributes a small piece of the puzzle until the final product is developed or the goals of the initiative are achieved. well as balance the various needs of the university at large. This work includes supporting researchers and students who need to find, manage, share, and/or preserve data. Additionally, data librarianship includes supporting the development of workflows at the university or college level that will support or facilitate better practices in research data management and 
improving open access to data and other non-traditional research products. In all of these interactions, I must stay aware of the different motivations and needs of the people I am supporting in my work as well as the new developments/cultural norms in the open science communities on which my work touches. When done well, research data management and stewardship leads to success from multiple sides-a researcher shares their data or software and receives credit for their work while others learn from and even build on the work already completed by that initial researcher.

When working on a project designed to support a heterogeneous community, such as you often find in open science, each collaborator's expertise and knowledge contributes a small piece of the puzzle until the final product is developed or the goals of the initiative are achieved. For example:

- Without the funder perspective, perhaps there would be no one in the room to incentivize open practices.

- Without the perspective of certain tool builders, developing a format compatible with citation managers might be forgotten.

- Without the librarian perspective, discovery for re-use or repurposing might be undervalued.

- Without archivist representation, the complexity of preservation could be disregarded.

- Without researcher collaboration, test cases and pain points may be overlooked.

Two specific examples follow.

\section{Example 1. Radical Collaboration in Support of Open Science: Software Citation}

The Software Citation Principles ${ }^{1}$ published in 2016 by FORCE11 came out of a multi-part need observed by the research community and 
likely were informed by many simultaneous projects. For many users of these principles, they might appear to simply be filling a need: to cite one of their sources for a publication. However, citing software serves the community in many ways, such as increasing the recognition of software as a research product, allowing for more representation of various forms of research contribution, and amplifying the vital contribution of developers to the scholarly community. These principles were developed by a working group including researchers from diverse disciplines, information professionals, and tool builders coming together with a common purpose. These different perspectives were necessary for a robust outcome. In order to fully meet the needs of the range of communities, the authors of the FORCE11 citation principles needed to first learn what these needs were. In my experience, individual contributors to the work of supporting open practices in the scientific software ecosystem have multiple motivations and perspectives as to how to support research software in this ecosystem, the different roles that software plays, and how to best support the researchers creating and/or using/re-using software.

Implementing the Software Citation Principles remains a complex endeavor; although, it is arguably not as complex as implementing good software preservation practices. At least now that this precedent has been established, outreach to researchers about publication and preservation of software can be more easily tied to the system of academic credit. When approaching a researcher as a potential "donor" of their scholarly work to the open science ecosystem, leaning on the citability of software improves the alignment of this conversation with traditional motivations-"Publish or perish;" "Cite it or it didn't happen."

\section{Example 2. Radical Collaboration to Preserve Informal Astronomical Communications}

A few years ago, several astronomers from the blog Astrobites, ${ }^{2}$ and other social, online, astronomy and astrophysics communities, 
noticed how much information they communicated via these informal platforms and the significance of these communications to their research discipline at large. Recognizing that these communications serve the same purpose now as letters did in the past, these researchers reached out to special librarians with a variety of skills, myself included, for help preserving these communications for posterity. In order for this project to start up successfully, we needed to understand the researchers' desires and vision for the preserved material. Questions such as "How important is the look and feel of the original?" and "Are comments part of a work?" were workshopped collaboratively by information professionals and researchers. This led to a general formation of an ideal output and workflow. The curation of the material ingested into the preservation platform would be carried out by expert domain

Each individual's expertise and perspective was needed in order to develop a successful radical collaboration. researchers, and facilitating this curation was a key requirement for success. Considerations such as supporting either an "opt out" or "opt in" option, as well as the writing of a disclaimer, were considered as alternatives to a formal donor agreement, because of the challenges inherent in establishing consent, terms, and conditions for automatically ingested digital media.

As these conversations continued, the librarians researched options for capturing, curating, documenting, and preserving this material. From this research they connected with several tool builders and service providers who could help with the development of webhooks to deliver content to different social platforms and development of automated description for preservation platforms. After making some initial decisions as a group, the researchers and the librarians separately put together ideas and proposals for possible workflows.

As an unfunded, complex project, the development of this project continues slowly, but the work remains collaborative, allowing for the 
voices of a number of partners. In this case, astronomy librarians and information science graduate students needed to refer to the work of archivists in order to learn necessary considerations to bring to the researchers for feedback and decision-making.

\section{Conclusion}

In both of these examples, the central requirements of sharing openly without attachment to a single perspective, inviting many voices to participate in the discussion, and of focusing on the common goals, facilitated a successful solution. Each individual's expertise and perspective was needed in order to develop a successful radical collaboration.

\section{Endnotes}

1. Arfon M. Smith, Daniel S. Katz, Kyle E. Niemeyer, and the FORCE11 Software Citation Working Group, "Software Citation Principles," PeerJ Computer Science 2:e86 (September 2016), https://doi. org/10.7717/peerj-cs.86.

2. Astrobites blog, accessed December 5, 2018, https://astrobites.org/.

(C) 2018 Megan Potterbusch

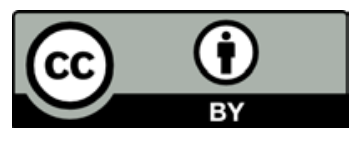

This article is licensed under a Creative Commons Attribution 4.0 International License. To view a copy of this license, visit https:// creativecommons.org/licenses/by/4.0/.

To cite this article: Megan Potterbusch. "What is Open Science, and How Can Radical Collaboration Facilitate It?" Research Library Issues, no. 296 (2018): 44-48. https://doi.org/10.29242/rli.296.6. 


\section{Seeking Sustainability and Inclusivity with Transparent Practices for Research Data Management}

Heather Soyka, Assistant Professor, School of Information, Kent State University

When thinking about how to encourage research data management education and activity, one option is to do that work in public. By demonstrating and modeling good practices, providing stepping stones and clear pathways from beginner to more advanced, and welcoming experimentation, questions, and contributions, communities can encourage public participation and a culture of growth and shared ownership for participants and future members.

As a member of the DataONE Community Engagement and Outreach Working Group, one of the projects that I shepherded was a revision of data education curriculum. The Working Group decided to update and convert older educational modules on research data management from static PowerPoint slides to slides in R Markdown, posted in GitHub, that are now open and customizable by the broader research data management community. ${ }^{1}$ Some of that work was completed with the intent of sustainability and currency of resources over time, with

...by placing this work in an open, shared repository, we also provided a window into what it looks like to do ongoing maintenance to these materials in a public place. the reasoning that anyone with a GitHub account could contribute or update at any point. However, by placing this work in an open, shared repository, we also provided a window into what it looks like to do ongoing maintenance to these materials in a public place. Who is contributing or maintaining or adding issues to the repository? That previously invisible work is now transparent; anyone can see which member created or worked on the lesson, whether a pull request has 
been submitted, or whether an issue has been closed.

While discussions about transparency and visibility are certainly not limited to the archival field, my thinking was at least partially informed by ongoing conversations about making the work of archivists more visible in descriptive practice. By making the identities of authors and maintainers clear, we demonstrate that people are making decisions to include this information. Providing this context can also connect people to the selection process: why was this added? When? What else is relevant? Adding the human context can also help us to understand and reflect on bias, neutrality, and gaps in our work and the work of others.

\section{Making Research Data Management a Social Activity}

By modeling transparent behavior for community engagement and outreach, this approach also suggests a way to encourage and engage with overlapping communities. Encouraging an open and welcoming approach to learning research data management tools, systems, and techniques is an avenue for connecting more deeply with researchers and others who both use and benefit from well-described, wellmanaged, accessible research data.

Encouraging social research data use and training may increase longterm engagement. The Data/Software/Library Carpentries ${ }^{2}$ are one solid example of a grassroots, community-driven approach to creating ownership and buy-in around particular training topics and techniques. But change does not necessarily need to come from a grassroots model. Building a shared vision of research and of research data management as community goals, rather than individual mandates, allows for the continued and sustained growth of a shared ecosystem of support. Finding ways to further align the professional incentives and systems for members of the broader research data management community can further help in this regard. But the need for a radical shift towards more inclusive, expansive collaboration still exists. 
As a researcher and an archivist by training, with a technological background and a strong interest in community building, I can see many parallels and intersections between the work of the scientific research community and the archives, preservation, and library/ information science communities. Building capacity by drawing stakeholders together to share tools and work towards common goals is useful and important for moving research data management practices closer to sustainability and long-term preservation. Unsurprisingly, there is a continued need for cross-pollination and interdisciplinary communities and cohorts to be fostered and facilitated by professionals with diverse backgrounds, skills, and interests. Sustaining, maintaining, and growing resources within and for communities is dependent on meeting the needs of current and future members. As membership ebbs and flows according to the needs of individuals and cohorts, maintaining a shared vision and mission is important to the sustainability of both community and resources.

Archivists and librarians are positioned to lead this charge. They are familiar with organizational models and with ensuring the preservation of resources over time, and are equipped to bring those and many

As membership ebbs and flows according to the needs of individuals and cohorts, maintaining a shared vision and mission is important to the sustainability of both community and resources. other professional skills to the research data management table. Archivists, librarians, and other information allies can provide leadership by developing inclusive

approaches, seeking and building collaborative partnerships, and insisting on research data management as a common good. Further, by investing in approaches to train and educate the research data management community in transparent, open, and welcoming ways, archivists and allies can frame the act of making good practices as an easy choice that contributes to a common, sustainable good. 


\section{Endnotes}

1. The project and its motivations are described more fully in Heather

Soyka et al., "Using Peer Review to Support Development of Community Resources for Research Data Management," Journal of eScience Librarianship 6, no. 2 (2017), https://doi.org/10.7191/ jeslib.2017.1114. The GitHub education module site is now the Data Management Skillbuilding Hub, DataONE, accessed December 6, 2018, https://dataoneorg.github.io/Education/.

2. The Carpentries website, accessed December 6, 2018, https:// carpentries.org/.

(C) 2018 Heather Soyka

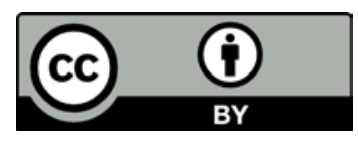

This article is licensed under a Creative Commons Attribution 4.0 International License. To view a copy of this license, visit https:// creativecommons.org/licenses/by/4.0/.

To cite this article: Heather Soyka. "Seeking Sustainability and Inclusivity with Transparent Practices for Research Data Management.” Research Library Issues, no. 296 (2018): 49-52. https:// doi.org/10.29242/rli.296.7. 


\section{Radical Collaboration: An Archival View}

Nancy Y. McGovern, Director, Digital Preservation, MIT Libraries

On the one hand, this is a great time to be an archivist working in academic libraries because there is growing interest and focus on archives and archival collections. On the other hand, this is a challenging time to be an archivist working in academic libraries because we are only at the starting point of building a better understanding of the domains and professions that contribute to the work of libraries, including archivists. As an example, different domains working in different organizational contexts have different understandings of what we mean by archival collections, manuscript collections, and special collections-this is a fundamental issue and an ideal starting point for a radical collaboration discussion. When I say:

- "archival collection" I mean the accumulated records of individuals and organizations that an archives is mandated or intending to keep based on a documented appraisal process;

- "manuscript collection" I mean the accumulated papers of individuals that an archives and manuscript repository of some kind has accepted responsibility for preserving; and

- "special collection" I refer to an accumulation of content that may be related by subject, media, form, creator, or other basis that is deemed by a collecting repository to have ongoing value.

I would never include archives as a type of special collection, and for me, special collections encompass more than rare books-both of which statements I have heard any number of people share in defining these terms. In addition, there are overlapping collections traditions that may make references to different types of collections confusing. In the archives and manuscripts tradition, manuscript collections often refer to personal archives that are typically associated with people of the parent institution of the archives. These manuscript collections are acquired much like other archival collections would be, by donation 
or deed of gift. In the rare book and manuscript tradition, manuscripts may refer to individual documents or similar resources that are generally created by external sources and are often purchased by the collecting repositories. For effective collaboration, it is useful to know when the same terms are used in different ways.

If libraries and archives start with questions about our shared areas of responsibility and concern, there will be a growing understanding of our roles, responsibilities, interests, and desired futures in our conjoined professions. Libraries and the library community far outnumber archives and archivists, so archives are most commonly found in academic libraries rather than separate organizations as they might be. How do we come together and achieve our individual and collective goals? Radical collaboration can help.

A challenge that appears to be increasing as practitioners and researchers from more domains become interested in archives and special collections is that key terms like "archives," "archivist," and "archiving" are used in different ways, especially in a digital context. We have seen that a lack of clarity on

If libraries and archives start with questions about our shared areas of responsibility and concern, there will be a growing understanding of our roles, responsibilities, interests, and desired futures in our conjoined professions. terminology leads to ambiguity and misunderstandings resulting from a belief that people are talking about the same things in the same ways when they are not, which works against productive collaborations.

To forge effective collaboration, it is important to explore perceptions of archives and archiving.

How do we develop a common understanding of what we do? 
To an archivist:

- Archives are organizations that collect the records of individuals or organizations, or the building (or portion thereof) housing archival collections.

- Archival practice is the professional discipline of administering such archival collections and organizations.

- The archival community refers to archivists anywhere who have training and expertise in archival principles and practice (for example, "SAA Core Values Statement and Code of Ethics"). ${ }^{1}$

The information technology profession, commonly referred to as IT, often uses "archives" and "archiving" to refer to aggregations of digital content and the storage of digital content respectively. Archivists would not typically view these activities and outcomes understood from this IT perspective as archival, nor do they equate to preservation, an essential, more robust, and collaborative concept.

How do we understand the roles that may be involved?

Non-archivists who curate content may use "digital archivist" to refer to anyone who works on digitized or other digital content of any kind, rather than to an archivist who is steeped in archival principles and practice. Historians and other researchers may refer to archiving to mean capturing, documenting, or recording history and milestones.

It is observably confusing to have these different understandings of these core concepts circulating within the same organizations, and it can be frustratingly hard to be heard and to bring attention to the need to develop shared and inclusive working definitions of these terms that are central to what archivists do. ${ }^{2}$

Community archives have become an important focal point in addressing equity, diversity, inclusion, and social justice in the context of collections. Good archival practice always involves working with 
creators of records to enable the long-term preservation of and access to organizational and personal archival collections. One definition of community archives is "collections of material gathered primarily by members of a given community and over whose use community members exercise some level of control."3 This term is worth mentioning here because of its significance today and because the term is used in different ways by different proponents. Often the content of community archives may provide important historical documentation and may include all kinds of valuable materials, though not include archival records. For collaboration, the community archives movement can provide opportunities for partnerships that include creators more actively as well as introduce challenges by limiting participation based on perceptions of who belongs at this table.

\section{Disambiguating Digital Archives and Digital Preservation}

Digital practice will continue to evolve-evolution is inherent in being responsive to ongoing technological change, a core principle of good digital practice. It is common in applied fields like ours that the terminology we use evolves as we develop our generations of good practice. As discussed in the introduction to this issue of $R L I$, developing working definitions is an effective technique for engaging in radical collaboration-begin with a shared understanding.

As we advance our practice, we specialize. Within our digital community, we have two paired yet distinct specialties-digital archives and digital preservation - that are often conflated, further diminishing the clarity we need for productive discussions when we collaborate. I use these working definitions for these key terms:

- Digital archives includes the range of real-time activities for all phases of the digital life cycle from the intent to create to creation and through the phases of archival curation: appraisal, description, access, reuse, and beyond, with the objective of ensuring that selected digital content is able to be preserved. 
- Digital preservation all activities organizations or individuals engage in over time to ensure long-term readability/usefulness of specified digital content.

These two specialties work in partnership and one person may be responsible for both, but the real-time activities of digital archives and the over-time activities of digital preservation have specific tools, techniques, requirements, and practice that we need to address. You might say that digital preservation picks up where digital archives leaves off, and there would be no need for digital preservation if not for digital archives. Depending on how the scope of digital archives is defined-specific to the management of archival content or generically referring to the management of digital content-digital preservation may have a broader mandate than digital archives, being responsible in many case for the preservation of digital content of all kinds.

One way to better understanding the similarities and distinctions between digital archives and preservation is to compare them side by side, the purpose of the Digital Archives and Preservation (DAP) Stack illustrated in Figure 1 below. ${ }^{4}$

Why "stack"? Because it is very common for organizations to take a technology-first or technology-only approach to digital practice. IT discussions often refer to the combination of technologies in use in their organization as their stack. Digital preservation includes as a foundational component infrastructure of the kind that the IT stack in part represents. The DAP Stack provides the organizational perspective to pair with the technological perspective of the IT Stack. There are six layers of good practice in the DAP Stack: governance, collection scope, acquisition, workflows, life cycle storage, and monitoring, with characteristics that distinguish real-time (digital archives) and over-time (digital preservation) planning and action. For radical collaboration, these are core concepts that need to be explored before building partnerships that are able to leverage the cumulative strengths of these partnered domains. 


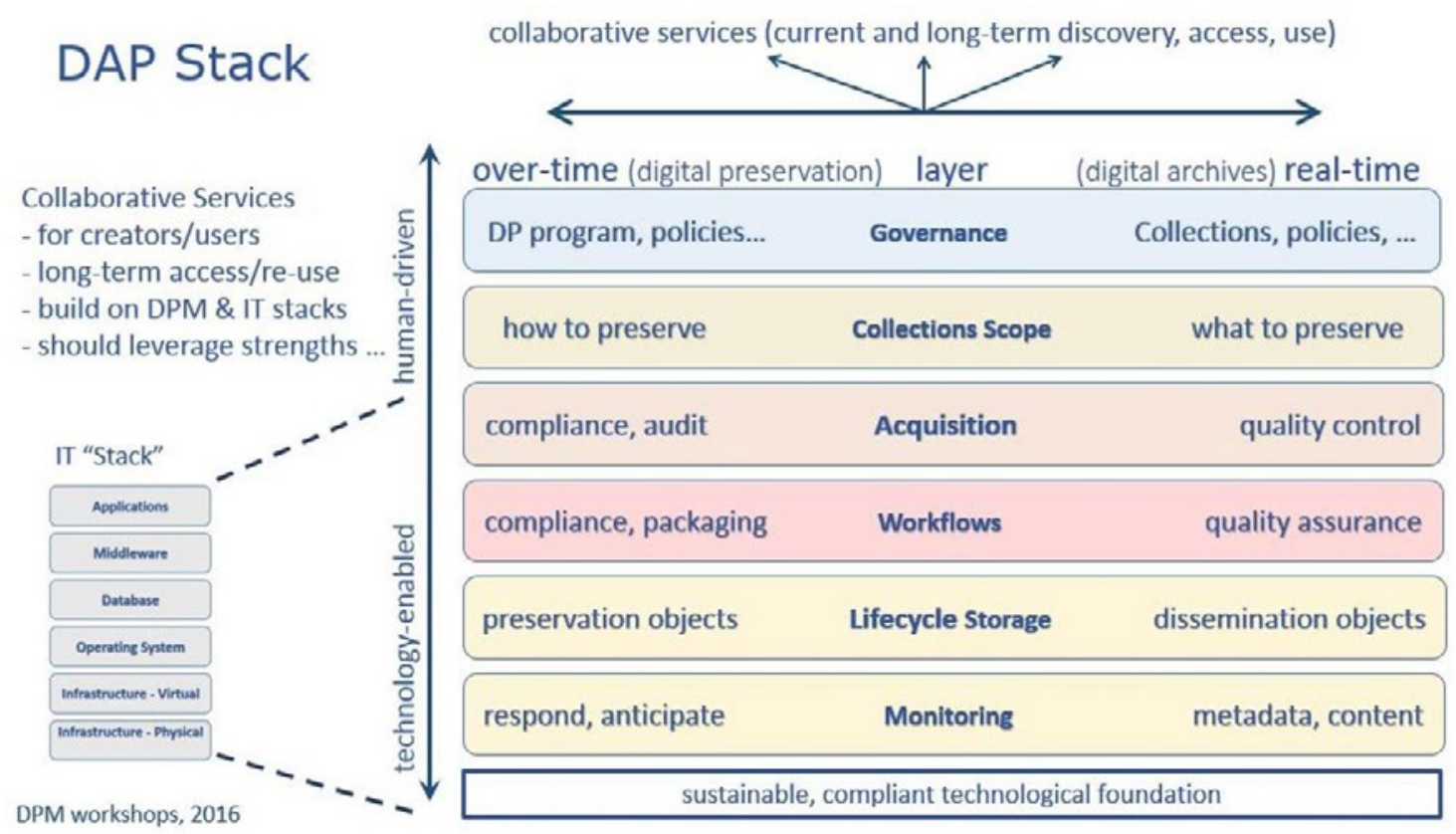

Figure 1. Digital Archives and Preservation (DAP) Stack

\section{Digital Practice and Research Outcomes}

The roundtable for digital practice discussed in the introduction to this issue of RLI is intentionally set for radical collaboration to achieve mutual objectives for research outcomes-to help researchers from the very start of their work to create, manage, preserve, enable discovery of, share, and reuse the outcomes of their work. There is wide agreement within the digital community that research data can take just about any form-by default that engages all of the domains (data science, archives, libraries, digital preservation, records management, museums, and software development). There is no hard line between research data and administrative and other data-the perception of data is based on context, need, and use. There are ongoing discussions of big data, which might be intentionally big (for example, ongoing often homogeneous accumulations of observational data) or might become big (for example, incremental, possibly longitudinal, often heterogeneous, accumulations of data). Some archivists have engaged in the long-term management of data of all kinds in digital form for decades and in physical form for much longer. No single domain 
The roundtable for digital practice...is intentionally set for radical collaboration to achieve mutual objectives for research outcomes.... owns or could own research data management across its life cycle. There is sometimes an awkward distinction made between active and archived data that may assign long-term responsibilities for data to archives and assume that current activities may be best done by other domains. That approach overlaps with but often does not include digital archivists and may complicate long-term preservation of data because essential discussions about sustainability requirements do not begin soon enough. In addition, there is an obvious and increasingly urgent need in research data management for records management, an allied field to archives, to help address retention and scheduling issues that would be tremendously helpful in the near-term and long-term management of research data. Radical collaboration will allow us to bring together the necessary knowledge, skills, and practice to work on research data together.

\section{Considerations for Radical Collaboration That Engages Archives and Archivists}

What will success look like when archives achieve professional inclusion within academic libraries? These are some considerations and suggestions for being inclusive of archives and archivists as we work to achieve radical collaboration:

- Remember that digital archives may refer to aggregations of archival records or to any digital content an individual or institution may be managing, whether or not the intention is to preserve the content.

- Examine the current and possible roles around digital practice to enhance collaboration, understanding that roles like digital archivist have many different definitions.

- Be aware that people often conflate digital archives and digital 
preservation, these are distinct if co-dependent domains.

- Make time to revisit institutional policies and practices to enable collaboration and inclusion-local archival practice in academic libraries has been established perhaps without input from archivists or may not yet reflect digital practice.

- Convene community discussion to explore distinctions between archival collections, manuscript collections, and special collections.

- Encourage the local and community-wide use of accepted working definitions of these and related terms and concepts that are the essence of an archivist's identity and a basis for professional inclusion.

Within the context of the Association of Research Libraries (ARL), examples of success might be convening directors of ARL archives to collaborate directly with archivists rather than through layers of organizational administration.

\section{Endnotes}

1. "SAA Core Values Statement and Code of Ethics," Society of American Archivists, accessed December 14, 2018, https://www2.archivists.org/ statements/saa-core-values-statement-and-code-of-ethics.

2. For example, Clifford Lynch and I had a productive discussion about the ambiguity in his article "Stewardship in the "Age of Algorithms" (First Monday 22, no. 12, December 4, 2017, https://firstmonday.org/ article/view/8097/6583) due to his various references to archives, archivists, digital archives, and archival practice that do not reflect archival practice as engaged in by archivists who adhere to archival principles and practice.

3. Andrew Flinn, Mary Stevens, and Elizabeth Shepard, "Whose Memory, Whose Archives? Independent Community Archives, Autonomy, and the Mainstream," Archival Science 9 (2009). 
4. For a more extended explanation about the concepts and components of the DAP Stack, please see this video: DataONE, "DPM 'Stack': A Management Infrastructure Frame for Digital Preservation that Parallels Technical Infrastructure," December 13, 2016, 53:11, https://www.dataone.org/webinars/dpm-"stack"-managementinfrastructure-frame-digital-preservation-parallels-technical.

(C) 2018 Nancy Y. McGovern

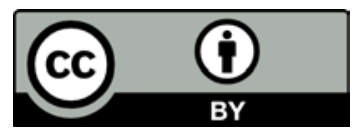

This article is licensed under a Creative Commons Attribution 4.0 International License. To view a copy of this license, visit https:// creativecommons.org/licenses/by/4.0/.

To cite this article: Nancy Y. McGovern. "Radical Collaboration: An Archival View.” Research Library Issues, no. 296 (2018): 53-61. https:// doi.org/10.29242/rli.296.8. 


\section{Forward Together}

Nancy Y. McGovern, Director, Digital Preservation, MIT Libraries

This issue of $R L I$ brings together some of the core concepts to engage within the broad digital community in radical collaboration, especially for managing research outcomes now and for the benefit of future researchers. This issue also shares some examples of collaborations that might reflect or even benefit from radical collaboration. This concluding section raises some possibilities and suggestions for exploration and discussion locally and within the broader digital community.

\section{Navigating Our Shared Space(s)}

To learn more about who you are working with, ask questions about what they do, how they identify professionally, what's important to them, how they arrived at this point in their careers and development, and what they would like to be able to do. We may think we already know and we will very likely be surprised by the answers if we take the time to ask. When someone asks me what I do. I often respond that:

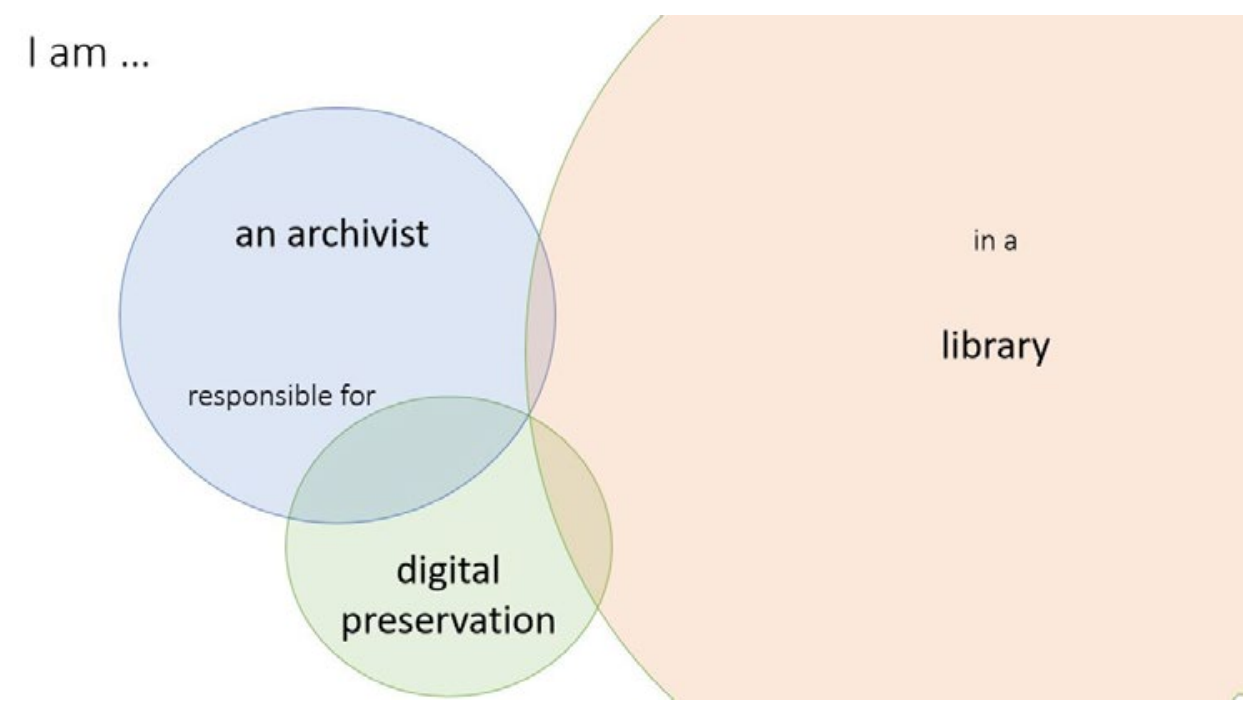

Figure 1. What do you do? 
The sizes of the circles suggest the relative sizes of the domains, but the overlapping of the circles are not intended to depict the ways in which these domains do, should, or could interact.

What would your response be?

\section{What Could Radical Collaboration Look Like?}

The examples shared by contributors to this issue of $R L I$ reflect current and recent efforts to collaborate in and around research data management within the digital community. Characteristics of radical collaboration abound in these examples. The following questions are considerations for new or reinvigorated efforts to achieve radical collaboration:

- Did you include a representative group that reflects the inclusion framework in defining the problem statement at the start of the effort?

- Is there room at the roundtable for more contributors as needed?

- Is it possible to incorporate ideas from the whole roundtable or compromise on reflecting the cumulative members all along the process (for example, engaging in a project, developing a programmatic effort, envisioning new services, seeking solutions)?

- Is it possible for anyone who should know or wants to know about what is happening with the effort to find out through transparent communication, accessible documentation, an openness to feedback, and holistic outreach at venues across the breadth of the roundtable?

These are examples-there are many more possible characteristics of radical collaboration to try out. More specific examples of structures and themes that would adapt well to radical collaboration are below. 


\section{Example 1. Constructive Research Methodology Overview}

Constructive research methodology originated in computer science. A number of applied domains have adapted it for their use and it is a great fit for distributed digital practice and radical collaboration. The possible outcomes from constructive research methodology include conceptual constructs, models, methods, and implementation. Constructive research methodology is one example of an exploratory research methodology. Conclusive research as depicted in Figure 2 is much more common and familiar, but exploratory research is a necessary part of what we do in developing generations of digital practice in response to ongoing technological change.

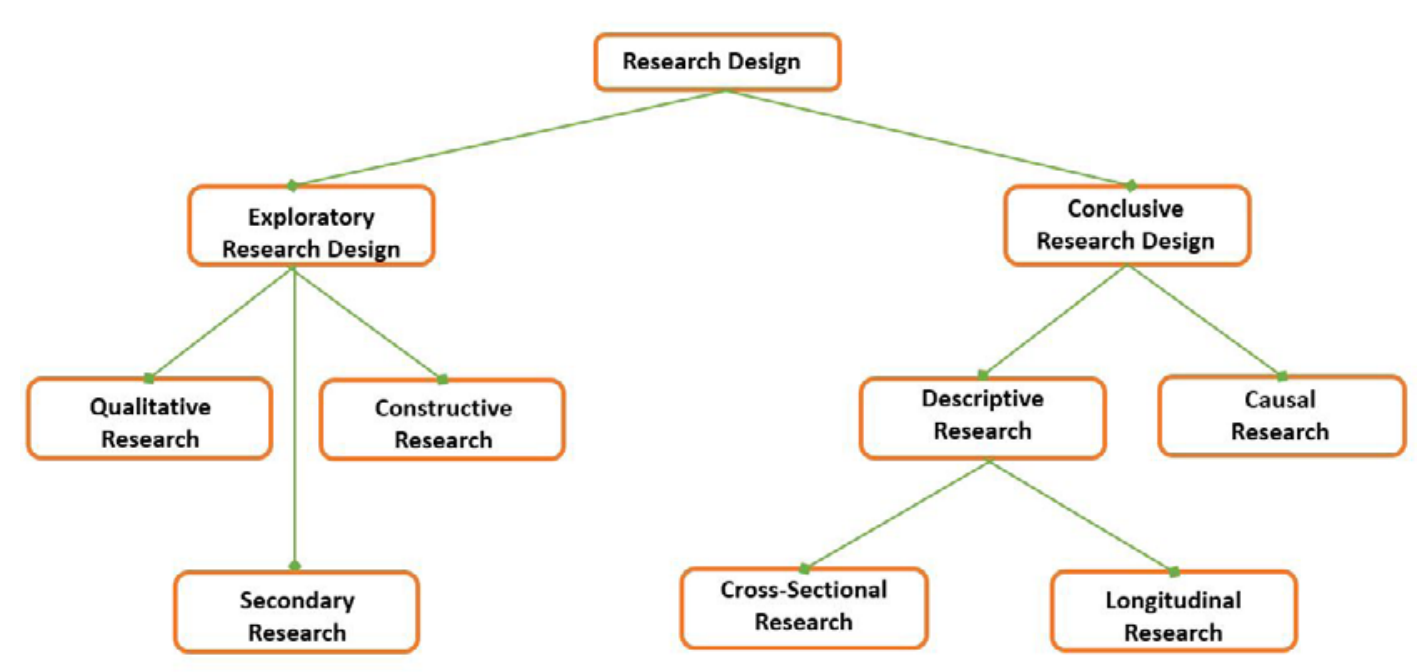

Figure 2. Context for exploratory research in research methodology ${ }^{1}$

A look at the steps of the methodology illustrate how this approach to exploratory research-based practice and practice-based research aligns with digital practice:

1. Find a relevant practical problem with research potential.

2. Obtain a general and comprehensive understanding of the topic.

3. Build an innovative solution (or construct). 
4. Demonstrate that the solution works.

5. Show the theoretical connections and research contributions of the solution.

6. Examine the scope of applicability of the solution.

Constructive research methodology is collaborative, iterative, and exploratory by design. The steps could be a recipe for engaging in radical collaboration for research data management problems and challenges.

\section{Example 2. Storytelling as a Digital Preservation Strategy}

The second example is storytelling for digital preservation, an emerging area that I am working to initiate and collaborate on across domains. ${ }^{2}$ With colleagues from oral history, audio-visual preservation, and software preservation, we made a start on a community discussion of storytelling for digital preservation at the iPRES 2018 conference. $^{3}$ Persistent challenges in each generation of technology are scalability and complexity. Storytelling would help address both challenges for the long-term preservation of complex digital content by providing and supporting layers of information about the content, the creators, the users, the curators, and the iterative and cumulative relationships among all of them with sufficient context for current and future users and other stakeholders to navigate as they choose. It would be possible to convey the significance of complex digital content, in whatever state the content itself makes its way into the future. Storytelling as a digital preservation strategy would enable non-linear, interactive, and story-driven approaches to the content. The same technologies that make machine learning, artificial intelligence, computational practice, and related hot topics in current community discussions possible, in part, enable storytelling digital preservation strategy. Storytelling as a digital preservation strategy would be best achieved through radical collaboration at the roundtable for digital practice. 


\section{How Can We Achieve Radical Collaboration?}

As we move towards realizing good practice for distributed digital practice, radical collaboration is both necessary and mutually beneficial. These are some considerations for successfully engaging in radical collaboration:

- Be sure everyone who should be or wants to be at the table is, allowing room for more seats as our awareness grows and to accommodate the unexpected guest.

- If it is not possible to have everyone who might need or want to sit at the table, ensure holistic communication to maximize their ability to contribute and follow along the whole of the process.

- Come to the table with questions not answers, the best way to build understanding and avoid bringing in our own biases and (mis)perceptions.

- If you haven't learned something in coming to the table, sit longer, ask more questions, and continue to listen.

- Be sure to reset the table as needed to adapt to the different perspectives that might contribute to collaborations to address our new and changing challenges and priorities.

- Remember to never assume you're chairing even if you sent out the invite to join the table-an innate strength of the roundtable for radical collaboration is by definition there is no head.

- Remember to value your knowledge and that of others; bring your whole self and be courageous-you may be the only one with your perspective and it needs to be heard.

- Prioritize the common goal over any single "right" approachradical collaboration allows for the greatest cumulative impact with an awareness of the needs and contributions of the whole table.

What would you add? 
Radical collaboration takes effort and practice and time, and the outcomes we will be able to achieve together will be worth it. Let's get going!

\section{Endnotes}

1. This research design classification diagram was adapted from a version that was developed by the Research Design Method company with examples of exploratory research expanded.

2. Informed and inspired by the 2017 "Update or Die" conference that was hosted by the Phi Centre and the MIT Open Documentary Lab in Montréal, Québec, Canada, https://phi-centre.com/en/event/ update-or-die/.

3. Jessica Meyerson (moderator), Nancy McGovern, Jimmy Fournier, and Darold Cuba, "Storytelling and Digital Preservation: Creators and Curators" (iPRES 2018, 15th International Conference on Digital Preservation, Boston, Massachusetts, September 27, 2018), https://osf. io/u5w3q/wiki/home/.

(C) 2018 Nancy Y. McGovern

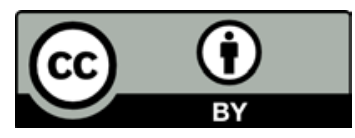

This article is licensed under a Creative Commons Attribution 4.0 International License. To view a copy of this license, visit https:// creativecommons.org/licenses/by/4.0/.

To cite this article: Nancy Y. McGovern. "Forward Together." Research Library Issues, no. 296 (2018): 62-67. https://doi.org/10.29242/rli.296.9. 


\section{/ ASSOCIATION \\ LIBRARIES}

\section{Research Library Issues}

Research Library Issues (RLI) focuses on current and emerging topics that are strategically important to research libraries. The articles explore issues, share information, pose critical questions, and provide examples. Suggestions for potential themes, articles, and authors are welcome. Please submit suggestions via this online form.

ISSN 1947-4911 https://doi.org/10.29242/rli

Executive director: Mary Lee Kennedy

Editor-in-chief: M. Sue Baughman

Managing editor: Kaylyn Groves

(c) 2018 Association of Research Libraries

ARL policy is to grant blanket permission to reprint as long as full attribution is made. Exceptions to this policy may be noted for certain articles. This is in addition to the rights provided under sections 107 and 108 of the Copyright Act. For more information, contact ARL Publications, pubs@arl.org.

Current and back issues are available on the ARL Digital Publications website, publications.arl.org/rli. The website is also where you may sign up for alerts to new releases of Research Library Issues.

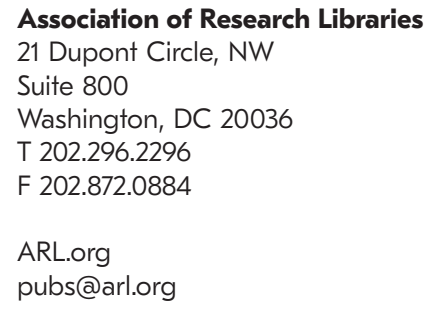

T 202.296.2296

F 202.872.0884

ARL.org

pubs@arl.org 